\title{
HÁBITOS ALIMENTARES, INFECÇÃO NATURAL E DISTRIBUIÇÃO DE TRIATOMINEOS DOMICILIADOS NA REGIÃO CENTRAL DO BRASIL *
}

Oswaldo Paulo Forattini **
José Maria Soares Barata $* *$
Jair Lício Ferreira Santos** $* *$
Antonio Carlos Silveira $* *$

FoRATTINI, O, P. et al. Hábitos alimentares, infecção natural e distribuição de triatomineos domiciliados na região central do Brasil, Rev. Saúde públ., S. Pauio, 16:171-204, 1982.

RESUMO: Apresentam-se as informações obtidas no inquérito triatomíneo levado a efeito na região central do Brasil. As características biogeográficas incluem a existência de áreas abertas dos cerrados e amplas faixas transicionais com outras feições paisagísticas. Dentre estas destacam-se a floresta tropical atlântica e a presença de extensas inclusões florestadas (florestas, galerias e capões de matas de diferentes ordens de grandeza). No periodo de $1975 / 1980$ foram examinados 3.160 triatomíneos coletados no ambiente domiciliar, objetivando detectar a presença de sangue ingerido e de infecção natural por Trypanosoma tipo cruzi. Por ordem de frequência, as espécies encontradas foram 'Triatoma infestans $(43,5 \%)$, Triatoma sordida $(33,0 \%)$ e Panstrongylus megistus $(23,5 \%)$ e algumas outras menos frequentes. A presença de sangue foi detectada em $35,9 \%$ e a infecção em $2,2 \%$ desse total de espécimens examinados. Na mobilidade alimentar obteve-se coeficientes gerais de $54,0 \%$ para ave e $30,0 \%$ para homem. De maneira especifica, revelaram-se apreciáveis níveis de antropofilia para $\boldsymbol{T}$. infestans e de ornitofilia para T. sordida. Quanto a P. megistus, se bem que encontrado frequentemente com sangue de mamiferos, apresentou também boa presença de sangue de ave. A presença de sangue humano em exemplares coletados no peridomicílio evidenciou a ocorrência de mobilidade espacial, em especial modo por parte de $\mathbf{P}$. megistus e T. sordida. A distribuição geográfica mostrou o caráter autóctone de 'T. sordida em relação ao domínio de cerrado, com poder invasivo para o das áreas florestadas. $O$ inverso verificou-se com relação a $\mathbf{P}$. megistus, enquanto que $\mathbf{T}$. infestans revelou seu aspecto invasivo para ambas as regiões, sob influência da atividade humana. Os resultados permitem concluir que, na transmissão regional epidemiologicamente signicante da tripanossomías a americana, desempenha papel relevante $o$ ' $\boldsymbol{~ . ~ i n f e s t a n s ~}$ em primeiro lugar, e o P. megistus, em segundo. Este poderá vir a ter maior atuação, na ãependência de fatores vários, como a sua capacidade de invasão domiciliar. Quanto a $\mathbf{T}$. sordida, na atualidade, representa risco potencial de

* Realizado com auxilio financeiro do Centro Brasileiro de Estudos Entomológicos em Epidemiologia (CENTEP) e do Conselho Nacional de Desenvolvimento Científico e Tecnológico (CNPq) (Processo PDE 10-1-01), com o apoio lcgistico da Superintendencia de Campanhas de Saúde Pública (SUCAM) do Ministério da Saúde.

* Do Departamento de Epidemiologia da Faculdade de Saúde Pública da Universidade de São Paulo - Av. Dr, Arnaldo, 715 - 01255 - São Paulo, SP - Brasil.

*: Da Superintendência de Campanhas de Saúde Pública (SUCAM) do Ministério da Saúde, Esplanada dos Ministérios, Bloco 11 - 70000 - Brasília, DF - Brasil. 
FORATTINI, O.P. et al. Hábitos alimentares, infecção natural e distribuição de triatomineos domiciliados na região central do Brasil. Rev. Saúde públ., S. Paulo, 16:171-204, 1982.

infestação ou reinfestação das habitações. O controle rotineiro, mediante a desinsetização domiciliar deverá fornecer bons resultados, com a eliminação da transmissão nesse ambiente. Todavia, continuará o risco de reinfestação, pelo menos no peridomićlio face aos focos extradomiciliares de $\mathbf{P}$. megistus e T. sordida. Isso implicará, necessariamente, vigilância cuja eficiência estará na dependência da continuidade das pesquisas.

UNITERMOS: Tripanossomiase americana. Triatomíneos, região central do Brasil. Triatomíneos, hábitos alimentares. Triatomíneos, infecção natural. Triatomíneos, domiciliação.

\section{INTRODUÇAO}

Em publicação anterior descreveu-se programa de estudos destinado à obtenção de conhecimentos mais detalhados sobre os aspectos regionais, no Brasil, do comportamento alimentar de populações domiciliadas de Triatominae. Nessa oportunidade, foi focalizada a região Nordeste $e, \operatorname{com}$ os dados obtidos, pôde-se conseguir subsidios para melhor entendimento do mecanismo de domiciliação desses insetos (Forattini e col.16, 1981). Desse modo, a meta final reside na possibilidade de avaliar o potencial de reinfestação das casas e a conseqüente probabilidade de retorno da transmissão domiciliar da tripanossomiase americana. Aspira-se, pois, a que tais informações se constituam em elementos úteis na orientação da vigilância epidemiológica.

Partindo-se da hipótese de que tal sinantropia é estimulada pela modificação do ambiente, no sentido de transformá-lo em terreno aberto graças à destruição da cobertura vegetal primitiva, procurou-se distribuir os dados obtidos pelas regiōes naturais, identificadas mediante aspectos paisagísticos. Estes basearam-se na consideração de áreas nucleares e vizinhas, ou seja, de transição (Forattini ${ }^{11}, 1980$ ). Seguindo essa conduta, no presente trabalho são apresentados os dados obtidos nas feições paisagísticas correspondentes aos cerrados e às áreas a eles adjacentes.

\section{REGIAO ESTUDADA}

A região focalizada corresponde ao domínio dos chapadões recobertos por cer- rados e penetrados por florestas-galeria (Ab'Sáber 1,2, 1971, 1977). A delimitação da regiăo nuclear dos cerrados foi realizada por critérios fitogeográficos em morfoclimáticos (Hüeck, 1972; Ab'Sáber, 1971), tornando possível identificar um espaço poligonal irregular para o conjunto dos cerrados do Brasil Central, do Sul de Mato Grosso aos chapadões do Maranhão. Esta "core area" se apresenta como um continuum fisiográfico e ecológico, da ordem de 1,8 milhão de $\mathrm{km}^{2}$. No entanto, a delimitação linear da área nuclear em face das complexas áreas de transição que a envolvem, constitui-se numa tarefa bastante complexa e dificil. Dessa maneira, as linhas limitrofes, a exemplo do considerado em outras ocasiões, terão de ser forçosamente aproximadas, permitindo maior ou menor elasticidade. Em vista disso, neste trabalho serão incluidos os dados obtidos em áreas da floresta tropical atlântica, embora se trate de outro domínio paisagístico. Objetiva-se, assim, visão mais geral da região centro-oeste do Brasil, que tem nos cerrados a sua parte dominante. Assim sendo, serão aqui descritas as feições referentes a esse domínio e das áreas transicionais que, na sua parte setentrional, apresenta $\operatorname{com} 0$ domínio da caatinga.

Com tais premissas pode-se considerar a presença de faixa delimitante oriental, estendendo-se de norte a sudoeste (Fig. 1). $\mathrm{Na}$ sua parte setentrional, a separação é feita com o dominio das depressōes interplanálticas semi-áridas do nordeste, e que têm na caatinga sua área nuclear. A des- 
FORATTINI, O.P. et al. Hábitos alimentares, infeção natural e distribuiçăo de triatomineos domiciliados na região central do Brasil. Rev. Saúde públ., S. Paulo, 16:171-204, 1982.

crição desse limite foi feita em trabalho anterior, ressaltando o aspecto de ampla faixa transicional que abrange grande parte do território do Estado do Piauí e que, em direção sul, atinge a Chapada Diamantina, já em terras baianas (Forattini e col. ${ }^{16}$, 1981). Dessa forma, o leste do Estado do Maranhão e o oeste do Estado da Bahia, incluída aqui a porção média da bacia do rio São Francisco, situam-se neste domínio com a feição geral de campos cerrados (Galvão 17, 1955; Kuhlmann ${ }^{24}$, 1977). Todavia, o amplo caráter transicional dessa área faz com que varie, conforme os estudiosos do assunto, a sua inclusão no cerrado oll na caatinga. Eis que para alguns, como Hueck ${ }^{19}$ (1972), Hueck e Seibert ${ }^{20}$
(1972) e Alonso 3 (1977), ela é incluída no segundo desses domínios, adentrando a porção norte do Estado de Minas Gerais. De qualquer maneira, e para as finalidades das presentes pesquisas, quando do estudo da região nordeste, os municípios piauienses nela englobados foram considerados como mais próximos à caatinga, enquanto que os do sudoeste baiano o foram como participantes de área transicional (Forattini e col.16, 1981).

Ao sul do Estado da Bahia, a demarcação dos cerrados passa a apresentar aspectos de transição com 0 domínio florestal atlântico. Tal feição caracteriza-se pelo desenvolvimento de tipo de vegetação flo-

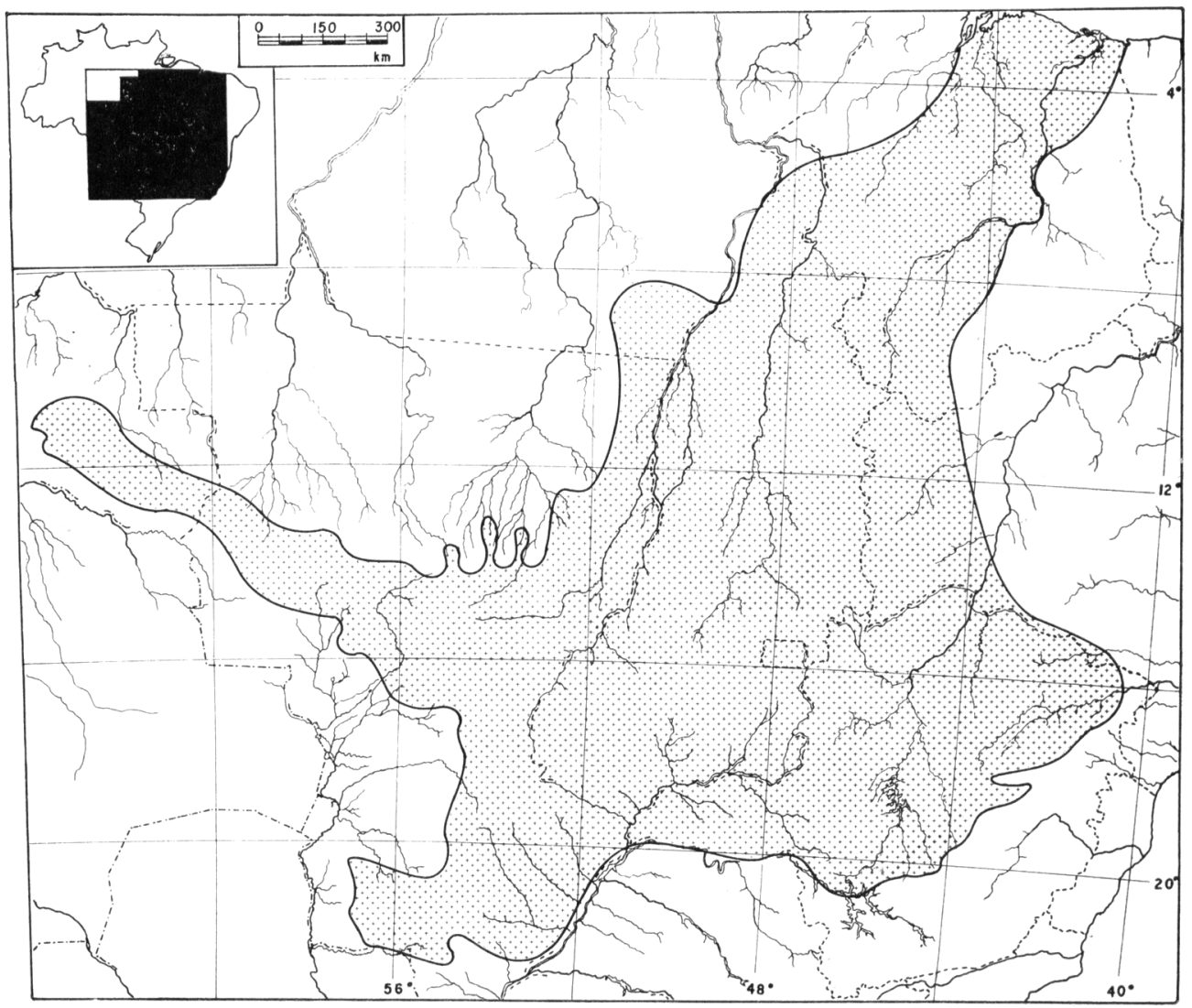

Fig. 1 - Localização do domínio dos cerrados no Brasil. 
FGRATTINI, O.P. et al. Hábitos alimentares, infeç̧ão natural e distribuição de triatomíneos domiciliados na regiăo central do Brasil. Liev. Saúde públ., S. Paulo, 16:171-204, 1982.

restal conhecido como "mata de cipó". Essa feição florística, representada pela floresta caducifólia não espinhosa, estende-se em direção meridional, entrando em território mineiro. Nesse percurso, interpõem-se entre a mata subcaducifólia tropical e as formações xerofiticas ocidentais até, aproximadamente, a altura do rio Araçuai (Alonso", 1977). Dessa maneira a linha limítrofe toma direçāo sudoeste, percorrendo o Estado de Minas Gerais até o vale do Rio Grande, que constitui o limite norte do Estado de São Paulo. Essa trajetória pode ser descrita como iniciando-se no vale do rio Jequitinhonha, nos limites com o Estado da Bahia. Acompanhando, a partir de Joaima, a borda oriental dessa bacia hidrográfica, atinge a Serra do Espinhaço na altura da Serra Azul de Minas após percurso, de acentuada sinuosidade, entre esta Itamarandiba. A partir desse ponto, toma direção sul seguindo o contorno daquele maciço montanhoso e, ao nivel de Belo Horizonte, dirige-se para o vale do Rio Grande alcançando-o no município de Formiga. A seguir, acompanha esse curso de água até a confluência o rio Paranaiba, para a formação do rio Paraná (Magalhães ${ }^{25}$, 1966; Moreira e Camelier 29, 1977; Alonso ${ }^{3}, 1977$ ). Seguindo a margem ocidental deste, perccorre a região meridional do Estado de Mato Grosso do Sul até a bacia do rio Ivinheima onde, essa hipotética linha limítrofe inflete-se novamente em direção oeste. Nesse percurso, e de maneira bastante sinuosa, atinge Ponta Porã. Em tal região, delimitante com o território paraguaio, o cerrado conflui com o chaco. Em terras brasileiras e em direção setentrional, volta a ocorrer a delimitação mas, desta vez, com a feição paisagística complexa do Pantanal. Isso se observa a partir de Bela Vista, acompanhando o rio Apa e, em seguida, subindo pela bacia do rjo Paraguai, englobando o baixo percurso dos rios que thes são afluentes, desde Miranda e Aquidauana ao sul, até Poconé, ao norte (Hueck e Seibert 20, 1972; Santos e col. $\left.{ }^{31}, 1977\right)$. A delimitação norte e ocidental corresponde ao traçado da linha divisória com a região amazônica e já descrita em trabalho anterior (Forattini 11, 1980).

O domínio dos cerrados constitui extenso sistema planáltico com alguns maciços de elevaçōes. O aspecto paisagístico é monótono, caracterizado por formações vegetais de tipo campestre, como os campos, campos cerrados e cerrados propriamente ditos, ao lado de feição florestal seca conhecido como cerradão. No entanto, tal divisão é apenas fisionômica, uma vez que a composição florística é comum a essas várias modalidades. De qualquer maneira, observa-se o predominio do aspecto savanóide, onde a vegetação arbórea apresenta-se esparsa, em maior ou menor grau, com individuos raramente ultrapassando os dez metros de altura. Ocorre ainda a presença de estrato arbustivo denso e, na superfície do terreno, de cobertura herbácea representada por gramineas c plantas rasteiras. Embora, de maneira geral, os solos sejam de fraca fertilidade primária, a variabilidade desse fator, aliada ao caráter perene dos cursos de água, faz com que aquela feição genérica seja descontinuada pela existência de inclusões florestais. Estas são representadas, seja pelas matas-galeria que acompanham os rios, seja pelos enclaves determinados graças à ocorrência de solos férteis. Alguns destes últimos atingem extensões consideráveis, e, provavelmente, se correlacionam ao dominio dos "mares de morros" florestados. Em território de Minas Gerais podem ser mencionados os que, sob a forma de floresta subcaducifólia tropical, constituem a ilha florestada denominada "Mata da Corda" situada na região leste do Triângulo Mineiro, além dos que se encontram no vale do rio Araguari, no oeste e sudoeste de Belo Horizonte, na região de $\operatorname{Arcos} e$ Pains, na de Patos de Minas e Tiros, e da denominada "Mata da Jaiba" ao norte de Montes Claros (Faissol 8 1957; Azevedo ${ }^{4}$, 1959; Alonso $\left.{ }^{3}, 1977\right)$. No que concerne a terras goianas destaca-se, com a mesma feição, a grande mancha conhecida como "Mato Grosso de Goiás", abrangendo regiāo que se estende desde as cercanias de Goiania e de Goiás até, ao norte, a Serra 
FORATTINI, O.P. et al. Hábitos alimentares, infecção natural e distribuição de triatomíneos domiciliados na região central do Brasil. Kev. Saúde públ., S. Paulo, 16:171-204, 1982.

Dourada. Inclui os vales de afluentes dos rios Araguaia e Tocantis, entre estes o rio das Almas, além de tributários do Paranaiba (Santos e col. ${ }^{34}$, 1977). Ademais dessas inclusões ocorrem outras, de menor amplitude, e que juntamente com os acima mencionados $e$ as matas galerias, fazem com que o domínio dos cerrados inclua potencial de florestas classificadas como de primeira classe (Weibel ${ }^{37}, 1948$; Hueck ${ }^{19}$, 1972). Todavia, é de se assinalar que tais áreas florestadas encontram-se, na atualidade, praticamente destruídas em virtude das alterações de origem antrópica que têm sofrido.

Além dessas matas de inclusão, há que se considerar a existência de outros aspectos, em especial modo, nas partes norte e nordeste da extensão dos cerrados. No que concerne à primeira, inclui a porção oriental do Estado do Maranhão, seguindo a margem esquerda do rio Paraíba, e a parte meridional do Estado do Piaui, a oeste do rio Uruçui-Preto. Alí a paisagem transicional caracteriza-se pela ocorrência de maior número de árvores, e pelo fato de apenas $15,0 \%$ das espécies vegetais presentes serem comuns a cerrado do planalto central. Por sua vez, a feição da caatinga apresenta inclusões, entre as quais pode ser mencionada a que ocorre no oeste baiano, abrangendo a região de Serra do Boqueirão, o alto curso do rio dos Cocos e Brejo Velho, e o municipio de Santana. Além disso é de se considerar que, para alguns, o norte do Estado de Minas Gerais pertence a esse domínio. De qualquer maneira, parece ponto pacífico que a parte média e alta da bacia do rio Jequitinhonha constitui mancha isolada de aspecto semelhante ao da caatinga (Kuhlmann ${ }^{24}$, 1977; Alonso ${ }^{3}$, 1977) (Fig. 2).

Quanto aos aspectos climáticos pode-se dizer que, apesar da enorme extensão deste domínio, são bastante uniformes, caracterizando o tipo de clima tropical semi-úmido. Não se apresentam aqui, de maneira acentuada, as influências orográficas, exceto nos conjuntos montanhosos mais elevados, que se encontram no Estado de Goiás. Nesse particular, admite-se, porém, alguma responsabilidade por diversidades térmicas, à oposição de amplas superfícies baixas, com menos de $200 \mathrm{~m}$, a extensas chapadas sedimentares e elevações cristalinas, onde a altitude varia de 700 a $1.200 \mathrm{~m}$. Na classificação de Koeppen inclui-se, de maneira geral, como "clima de savanas", ou seja, do tipo Aw correspondente ao tropical chuvoso com inverno seco e onde a temperatura média do mês mais frio é superior a $18^{\circ} \mathrm{C}$. Contudo, o extremo setentrional, compreendendo a parte norte maranhense e piauiense, classifica-se como Aw', uma vez que a estação chuvosa prolonga-se ali até o outono (Koeppen ${ }^{21}$, 1948). Pode-se dizer pois que o clima quente predomina em toda a região, pois apenas algumas áreas do sul de Goiás e de Mato Grosso do Sul mostram, nos meses de inverno, a ocorrência de temperaturas médias inferiores àquele nivel. A grande amplitude latitudinal, que se estende entre os paralelos de 3 e $22^{\circ}$ de latitude sul, contribui para a presença de diversificação térmica observando-se, ao norte de Goiás, que os valores médios no inverno chegam a ultrapassar os $24^{\circ} \mathrm{C}$. No que concerne ao ritmo estacional das chuvas, verifica-se o predomínio do regime tropical centrobrasileiro, com o máximo de precipitações no verão e o mínimo no inverno. Faz exceção, a referida parte setentrional do Maranhão-Piauí, onde ocorre o regime tropical da zona equatorial que, como se mencionou, apresenta intensa pluviosidade outonal e mínima no período primaveril. Desse modo, na região do dominio dos cerrados, considera-se a presença de clima quente e semi-úmido, com quatro a cinco meses secos, emprestando-lhe assim homogeneidade bastante grande. Com exceção de sua parte no extremo norte, esse aspecto é reforçado pelo sistema geral de circulação atmosférica. Esta, com seu aspecto caracteristicamete tropical, constitui fator poderoso para o quadro de uniformidade que se verifica na variação estacional da temperatura e das precipitações, com máximos na primavera-verão e mínimos no inverno (Nimer ${ }^{30,31}, 1979$ ). 
FURATTINI, O.P. et al. Hábitos alimentares, infeç̧ão natural e distribuição de triatomíneos domiciliados na região central do Brasil. hev. Saúde públ., S. Paulo, 16:171-204, 1982.

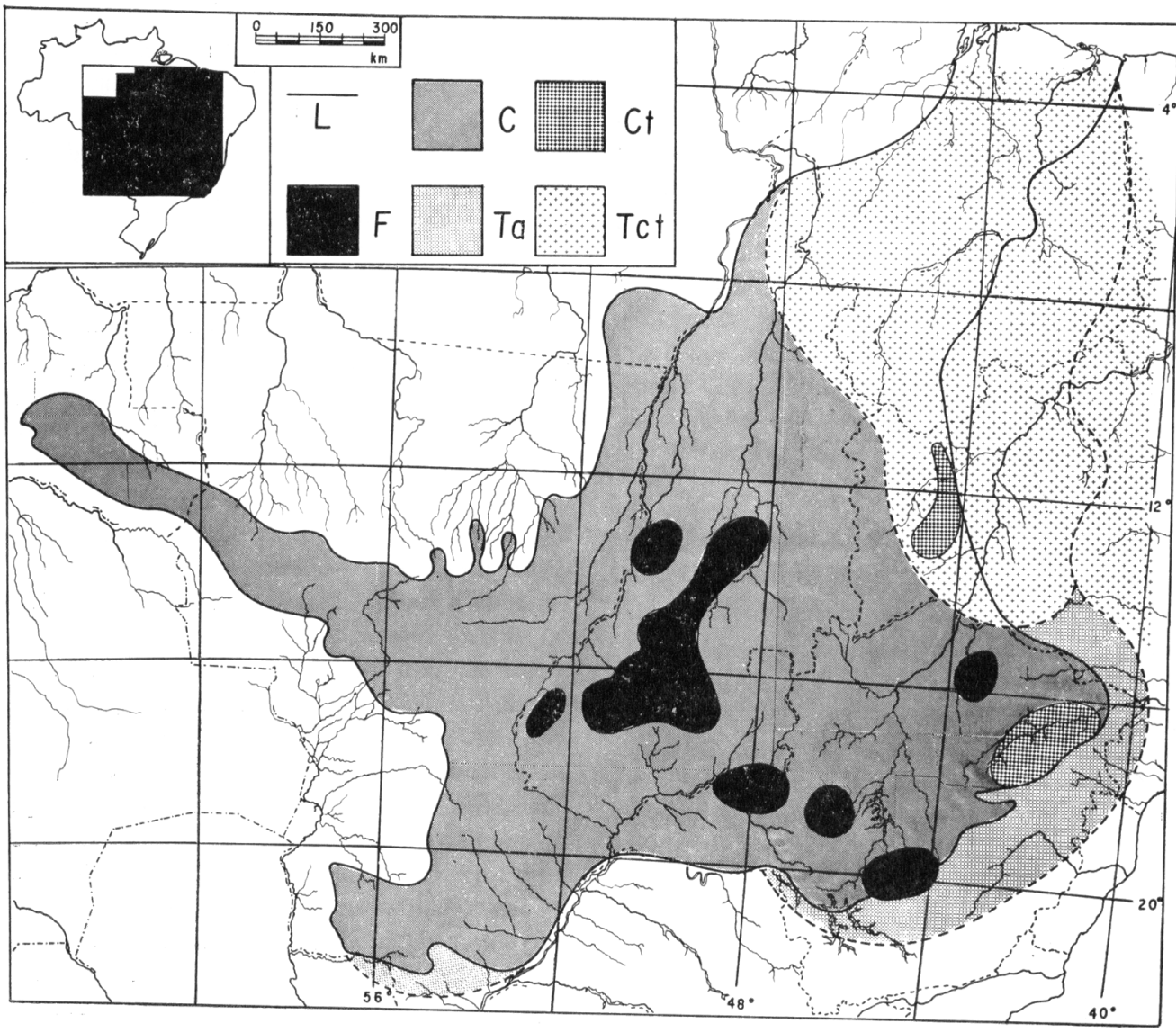

Fig. 2 - Distribuição geral das feições paisagísticas e fitogeográficas da região estudada. $C$ - Cerrado; $C t$ - Inclusões de caatinga; $F$ - Inclusões florestadas; $L$ - Limite da região estudada (cerrado); $T a$ - áreas transicionais com o domínio tropical atlântico (linha tracejada): Tct - Areas transicionais com o domínio da caatinga (linha tracejada).

Das descrições acima, ressalta a monotonia do conjunto paisagistico que caracteriza este domínio de chapadões recubertos por cerrados e penetrados por florestas-galeria. Na sua área nuclear apresenta-se como território marcadamente planáltico, em condições topográficas e climáticas bastante favoráveis (Ab'Sáber 1.2, 1971, 1977). A superfície do terreno é ligeiramente ondulada e freqüentemente interrompida por rios de variada envergadura, o mais das vezes acompanhados pelas citadas matas de galeria. A esse padrão de paisagem se contrapōem formaçōes diferentes, constituidas por escarpas elevadas de amplitudes variadas. Como já se mencionou, o aspecto da cobertura vegetal é o dos campos cerrados, cerrados e cerradões. A eles acrescentam-se as inclusões, florestadas ou não, também já referidas. A distribuição geral dessas feições vegetais pode ser observada na Fig. 2. Todavia, é de se mencionar os aspectos encontrados no extremo norte da região, ou seja, nas porções setentrionais dos Esta- 
FORATTINI, O.P. et al. Hábitos alimentares, infecção natural e distribuição de triatomineos domiciliados na região central do Brasil. Rev. Saúde públ., S. Paulo, 16:171-204, 1982.

dos do Maranhão e do Piauí. Estabelece-se alí ampla área de caráter transicional entre o domínio da floresta amazônica, a oeste, o da caatinga, a leste, e o dos cerrados, ao sul. O limite norte é constituído pela costa atlântica e a vegetação típica do litoral. Nessa extensão, as várias feiçōes de transição manifestam-se pela descaracterização, em maior ou menor intensidade, dos quadros paisagísticos desses domínios. A csse respeito já se mencionou o grau de diversidade ali apresentado pelo cerrado, em comparação com os caracteres que ele apresenta em regiões mais meridionais. Todavia, o que distingue essa área é a riqueza em palmáceas, dentre as quais sobressaem, pela importância econômica, o babaçú (Orbignya) e a carnauba (Copernicia). A partir daí, esses vegetais dispersam-se em direção sul, atingindo territórios matogrossenses e mineiros (Santos ${ }^{3 .}$ 1943; Fialho ${ }^{10}$ 1953; Kuhlmann 23 1953; Galvão 17 1955).

Sob o ponto de vista paleoecológico, a região abrangida nesta descrição inclui alguns possíveis refúgios, por ocasião da última época glacial. Em estudos com lepidópteros, Brown ${ }^{7}$ (1979) situa-os no que ele denomina de centro de endemismo e evolução do Araguaia. Com probabilidade variável de 60,0 a $100,0 \%$, abrange área do sul do Estado de Goiás, correspondente aos terrenos florestados da Serra Dourada e do "Mato Grosso de Goiás". Além desses, outros possiveis refúgios estariam em áreas menores localizadas em Mato Grosso do Sul, na bacia do rio Paraná, e no oeste da Bahia. Tais centros de endemismo poderiam incluir populações triatomineas que, a partir deles, teriam se dispersado e domiciliado sob pressão da atividade antrópica (Forattini 11, 1980).

Tem-se aventado a hipótese de que 0 aspecto aberto do dominio dos cerrados fosse devido à atuação humana que teria destruído a cobertura florestal primitiva ali existente. Todavia isso não corresponde à verdade, a não ser em regiões mais intensamente povoadas e nas inclusões florestadas as quais, na atualidade, acham-se praticamente destruídas (Hueck 18,19, 1957, 1972). Até pouco tempo atrás, os cerrados eram considerados impróprios para a exploração agrícolâ, motivo pelo qual sua utilização era relativamente reduzida. A construção de Brasília, em pleno domínio dessa feição paisagística, até certo ponto obedeceu a esse conceito. Contudo, o desenvolvimento das técnicas agricolas, com o preparo adequado do solo, pôde transformá-los em áreas produtivas. Tal fato, indo ao encontro de topografia e de condições climáticas favoráveis, resultou na abertura de novas fronteiras para a exploração agropecuária. Daí a incorporação, ao plano nacional de clesenvolvimento brasileiro, do potencial de recursos naturais dessa região, visando o aumento da produtividade. Em conseqüência, foram estimuladas as atividades para tal objetivo e encontra-se em andamento verdadeiro processo de transformação da paisagem natural. Ao lado disso, tem-se procurado estimular as pesquisas destinadas ao estudo das condições para a melhor utilização dessas extensas áreas (Weibel ${ }^{37}$, 1948; Faissol ${ }^{8}, 1957$; Ferri ${ }^{~}, 1977$ ). É de se prever pois, para futuro próximo, a intensa ocupação dessa grande região aberta. As modificações daí resultantes poderão dar origem a estímulos que tendam a modificar o comportamento de populações naturais. Entre estas, e para o assunto focalizado neste trabalho, importa considerar as de triatomíneos que assim poderão ser atraidas para o processo de domiciliação.

\section{MATERIAL E METODOS}

A coleta do material, o processamento em laboratório e o tratamento dos dados obtidos, obedeceram à mesma metodologia já descrita por ocasião de trabalho anterior, exceção feita do teste de duas proporções com aproximação normal, cuja utilização foi 
FORATTINI, O.P. et al. Hábitos alimentares, infecção natural e distribuição de triatomineos domiciliados na regiāo central do Brasil. Rel. Saúde públ., S. Paulo, 16:171-204, 1982.

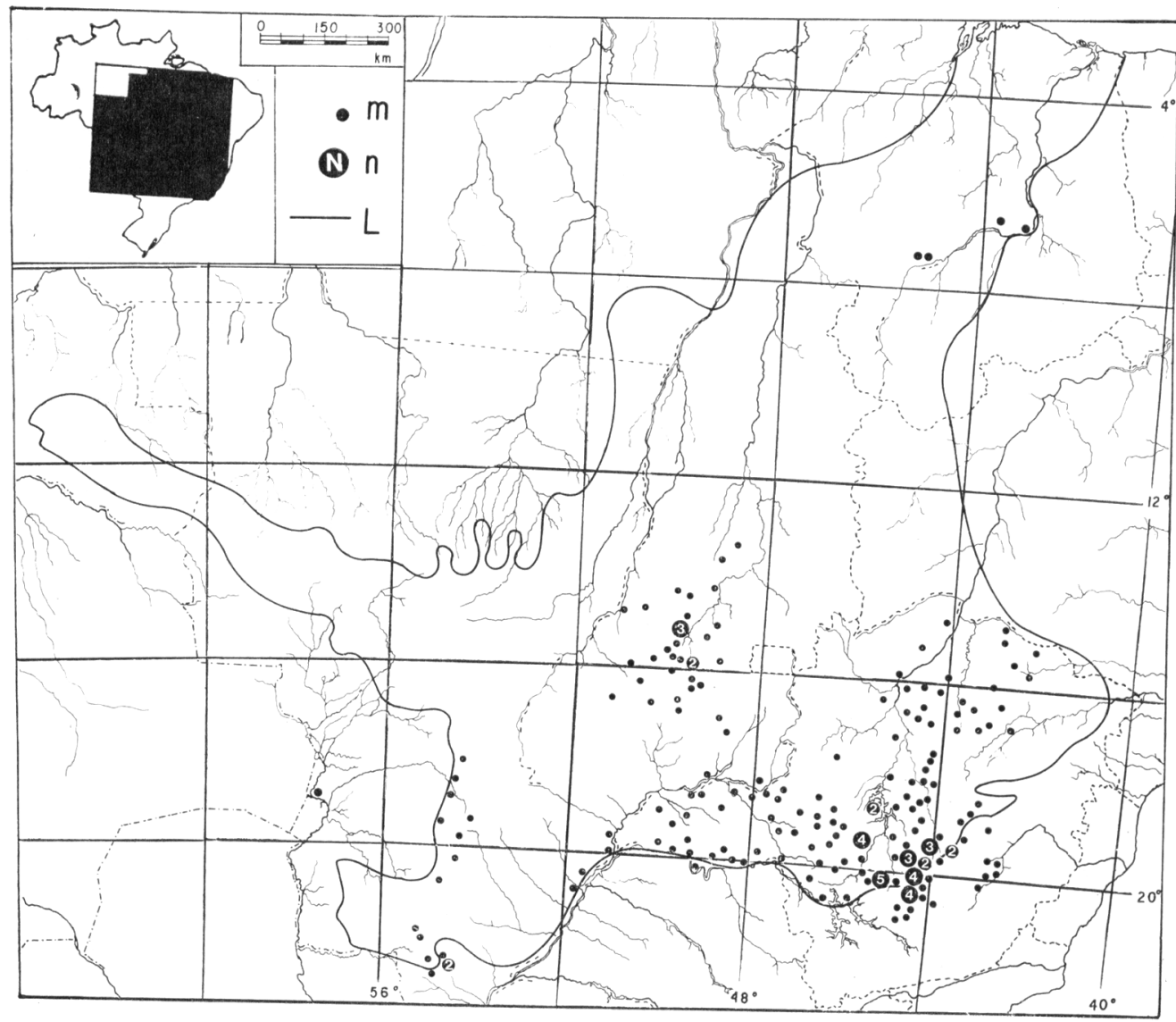

Fig. 3 - Localização dos municípios de procedência do material examinado. $m$ - municípi isolado: $n$ - conjunto de municípios próximos com o número correspondente (N): is - limite aproximado da região estudada.

julgada desnecessária neste trabalho (Forattini e col.16, 1981). A procedência dos espécimens submetidos a exame incluiu o total de 1.513 localidades, situadas em 198 municípios da área descrita, e cuja localização está representada na Fig. 3. A Tabela 1 expõe a distribuição dessas unidades, de acordo com as regiões biogeográficas e os Estados considerados. A distribuição individual, segundo esses mesmos critérios, acrescida das espécies encontradas, encontra-se no final deste artigo. Todavia, do material coletado excluiu-se o obtido nos dois municipios, de Corumbá (Estado de Mato
Grosso do Sul) e de Cristália (Estado de Minas Gerais). Tal atitude justificou-se pelo fato de a exigüidade desse número não permitir obter nenhuma informação útil refcrente às regiões do Pantanal e da Caatinga de inclusão, das quais foram, respectivamente, os únicos representantes nesta pesquisa. Por outro lado, cabem aqui as mesmas ponderaçoes, tanto as referentes a possiveis causas de erro como as concernentes aos critérios seguidos, e yue já foram expostas em trabalhos anteriores ( $\mathrm{Fo}$ rattini 11, 1980; Forattini e col.1", 1981). 
FORATTINI, O.P. et al. Hábitos alimentares, infecção natural e distribuição de triatomineos domiciliados na região central do Brasil. Rev. Saúde públ., S. Paulo, 16:171-204, 1982.

T A B E L A 1

Distribuição dos municípios de procedência do material examinado, por regiôes biogeográficas e Estados da Região Central do Brasil.

\begin{tabular}{|c|c|c|c|c|c|}
\hline Regiões Biogeográficas & Goiás & Maranhão & $\begin{array}{l}\text { Mato Gros- } \\
\text { so do Sul }\end{array}$ & $\begin{array}{l}\text { Minas } \\
\text { Gerais }\end{array}$ & Total \\
\hline Cerrado & 8 & 4 & 15 & 85 & 112 \\
\hline Floresta atlântica & - & - & 4 & 21 & 25 \\
\hline Floresta de inclusão & 27 & - & - & 32 & 59 \\
\hline Outras & - & - & $1^{*}$ & $1^{* * *}$ & 2 \\
\hline Total & 35 & 4 & 20 & 139 & 198 \\
\hline
\end{tabular}

\section{RESULTADOS}

Esta pesquisa implicou o exame de 3.160 triatomíneos, com a distribuição especifica seguinte:

\begin{tabular}{|c|c|c|}
\hline Espécie & No & $\%$ \\
\hline Panstrongylus megistus & 741 & 23,5 \\
\hline Triatoma infestans & 1.375 & 43,5 \\
\hline Triatoma sordida & 1.044 & 33,0 \\
\hline Total & 3.160 & 100,0 \\
\hline
\end{tabular}

Além dessas, foi possivel registrar o encontro esporádico de outras quadro espécies, no total de 26 exemplares. Os resultados referentes a estas serão relatados em parágrafo adiante.

No que concerne à distribuição relativa ao domicílio e peridomicílio, obteve-se 859 triatomineos no primeiro e 1.197 no segundo, excluidos 1.104 insetos para os quais essa informação não foi conseguida. Assim, desses 2.056 exemplares, $41,8 \%$ foram obtidos em moradias e $58,2 \%$ em anexos do ambiente peridomiciliar.
A presença de sangue ingerido pôde ser detectada em 1.133 do total já mencionado de espécimens examinados, e correspondendo a $35,9 \%$. Por sua vez, a infecção natural por Trypanosoma cruzi foi detectada em $2,2 \%$ dos tritomineos, ou seja, em 69 desses insetos. A distribuição que se observou para essas espécies acha-se representada nos mapas das Figs. 4, 5 e 6.

Mobilidade e especificidade alimentares A maioria dos triatomineos que se revelaram portadores de sangue ingerido, o foi para uma só fonte. Os dados gerais acham-se expostos na Tabela 2 onde se verifica que $73,7 \%$ dos insetos positivos acusaram conteúdo sanguíneo procedente de um só hospedeiro. A ocorrência de fontes múltiplas foi de $26,3 \%$, da qual $22,2 \%$ correspondeu a dois, a $3,8 \%$ a três e $0,3 \%$ a quatro tipos de sangue. Esta última foi muito pouco freqüente $e$ incluiu um exemplar de $P$. megistus e dois de $T$. sordida.

Considerando-se as reações positıvas para os vários soros, de acordo com as diversas 
FORATTINI, O.P. et al. Hábitos alimentares, infeç̧ão natural e distribuição de triatomineos domiciliados na região central do Brasil. Rev. Saúde públ., S. Paulo, 16:171-204, 1982.

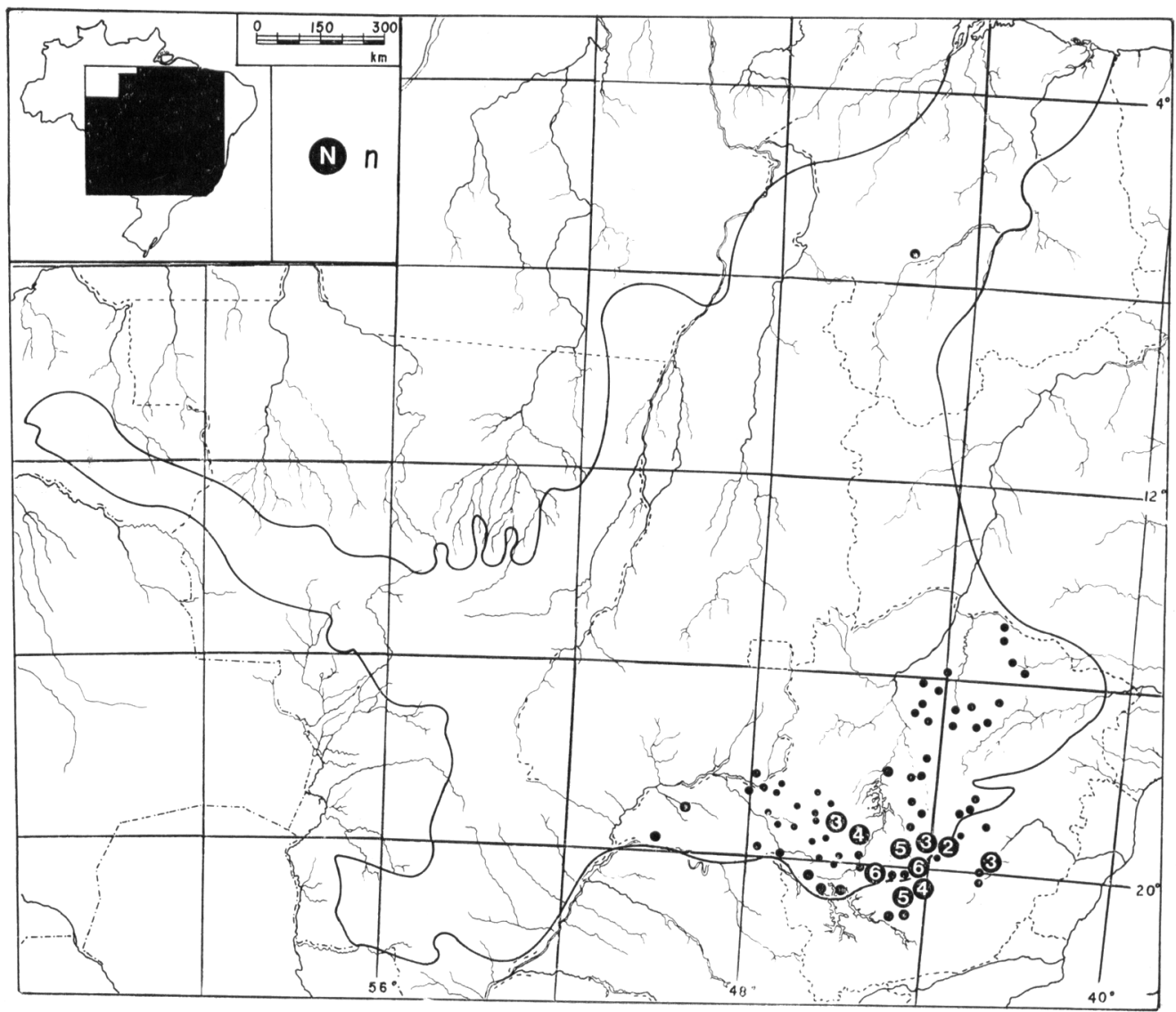

Fig. 4 - Distribuição de Panstrongylus megistus obtida pelos municipios trabaihados (Figura 3). Cada marca corresponde a um município e a diferença de diâmetros indica 0 aistanciamento entre eles. $n$ - conjunto de municípios próximos com o número correspondente $(\mathrm{N})$.

fontes, foi possivel obter os resultados seguintes:

Fontes

N:

Homem

444

Căo

Gato

113

Roedor

43

Marsupial

Ave

Total
$\%$

30,0

2,9

7,6

2,9

2,6

54,0

100,0
Observa-se pois que a ave e o homem foram os hospedeiros mais freqüentemente utilizados representando, em conjunto, $84,0 \%$ das reações positivas. A Tabela 3 mostra a distribuição desses resultados pelas espécies. Verifica-se assim que o $T$. infestans foi responsável por $57,4 \%$ das reações positivas para sangue humano, e o $T$. sordida o foi por $51,7 \%$ das para sangue de ave. Por sua vez, o $P$. megistus mostrou apreciável positividade para os vários hospedeiros, em que pese o escasso comparecimento de cão e roedor. Assinale-se ainda 
FORATTINI, O.P. et al. Hábitos alimentares, infeç̧ão natural e distribuição de triatomíneos domiciliados na região central do Brasil. Rev. Saúde públ., S. Paulo, 16:171-204, 1982.

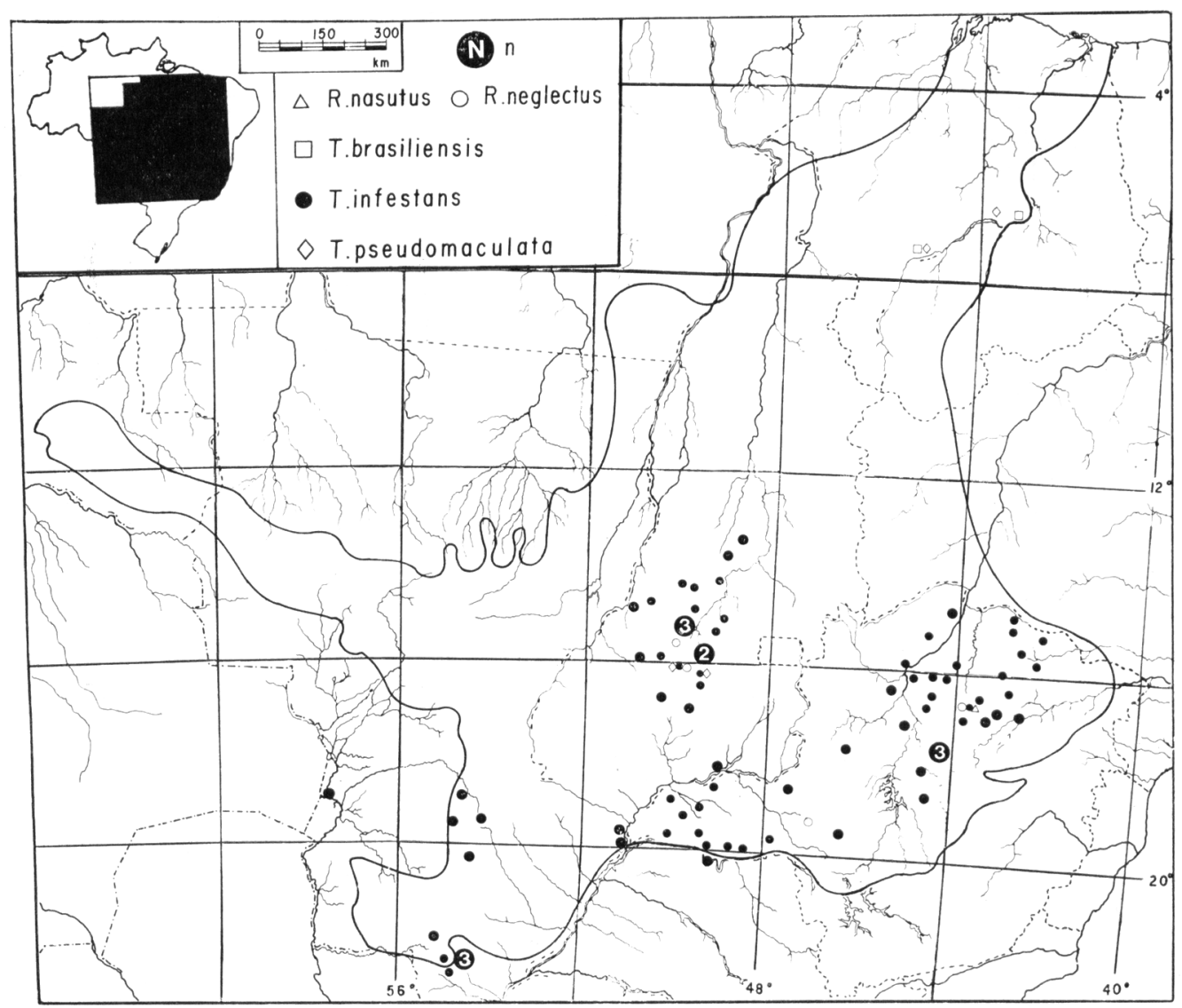

Fig. 5 - Distribuiçăo de Triatoma infestans e de algumas espécies menos freqüentes, obtida pelos municipios trabalhados (Figura 3). Cada marca corresponde a um municipio, e a diferença de diămetros indica o distanciamento entre eles. $n$ - conjunto do municípios próximos com o número correspondente $(\mathrm{N})$.

que só foi detectado sangue de marsupial em $T$. infestans o qual, por outro lado, revelou a menor positividade em relação à ave, correspondente a $15,5 \%$ das reações positivas para esse hospedeiro. Assim pois, os resultados evidenciaram apreciável mobilidade alimentar destacando-se, nesse particular, o $T$. infestans que transitou por todos os tipos de sangue que foram testados.

Com a finalidade de detectar possivel especificidade alimentar em relação ao sangue humano, procedeu-se à comparação do número de insetos que se revelaram positivos para esse hospedeiro, com o daqueles que mostraram positividade para outros tipos de sangue. Paralelamente, levou-se em consideração também o comportamento desses dados relativamentte ao número de fontes utilizadas. Os resultados encontram-se na Tabela 4. Pode-se observar que dos 1.133 triatominens que acusaram a existência de sangue no conteúdo intestinal, o total de $39,1 \%$ revelou a presença de sangue humano. Em relação às espécies 
FORATTINI, O.P. et al. Hábitos alimentares, infecção natural e distribuição de triatomíneos domiciliados na região central do Brasil. Rev. Saúde públ., S. Paulo, 16:171-204, 1982.

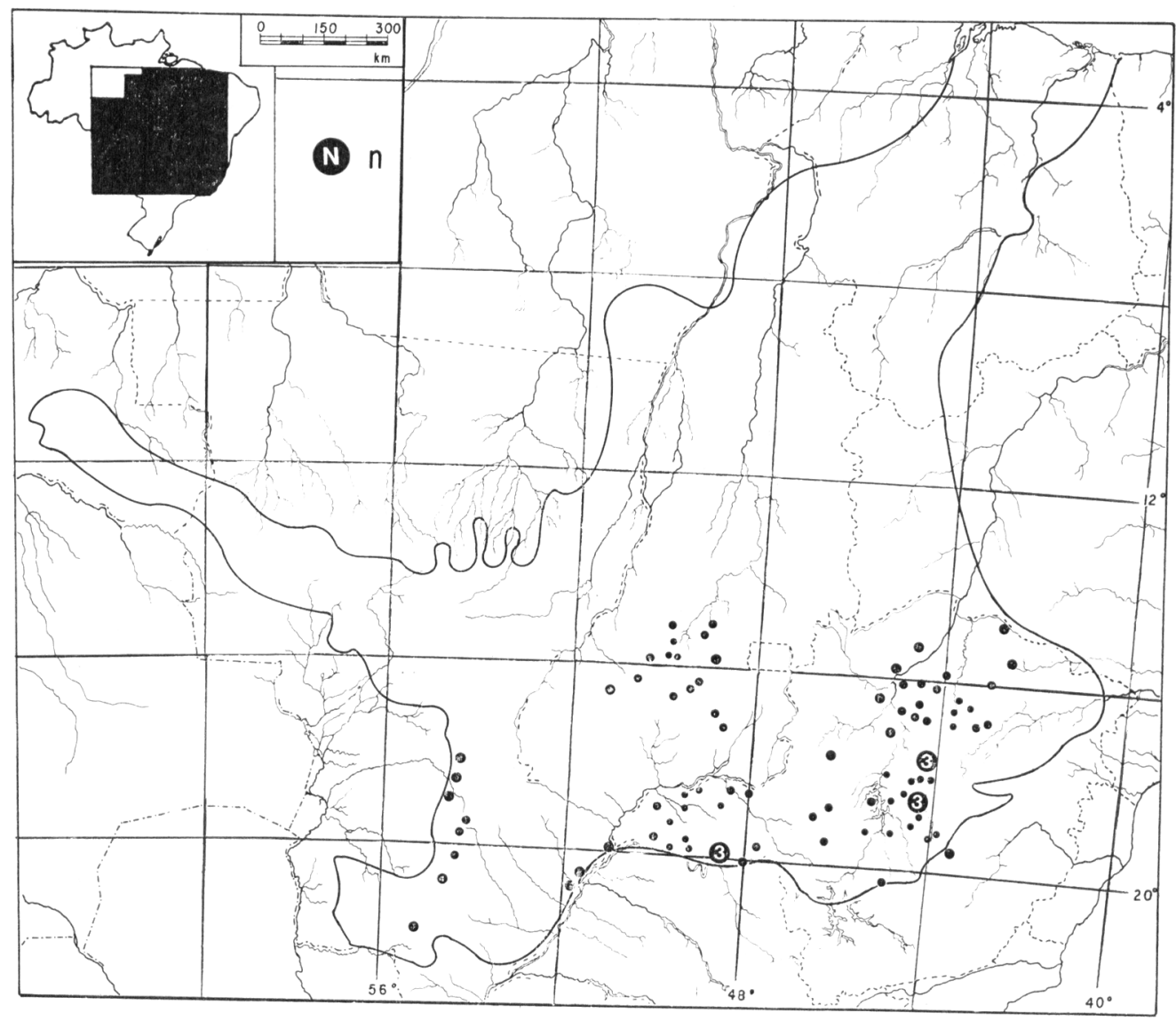

Fig. 6 - Distribuição de Triatoma sordida obtida pelos municipios trabalhados (Figura 3 ). Cada marca corresponde a um municipio, e a diferença de diâmetros indica o distanciamento entre eles. $n$ - conjunto de municípios próximos com a número correspondente $(\mathrm{N})$.

nota-se que, para $T$. infestans e $P$. megistus, respectivamente $70,8 \%$ e $31,9 \%$ evidenciaram alimentação em homem. Por sua vez, o $T$. sordida mostrou pequena participação, restrita a $18,9 \%$ dos exemplares reativos, mas com $81,1 \%$ de espécimens positivos para outros hospedeiros.

Foi feita a comparação do número de insetos positivos para homem e com uma só fonte, com o dos de igual positividade mas revelando mais de uma fonte. Como resultado, observou-se que os coeficientes para o hospedeiro humano, tendem a aumentar com a multiplicidade de repastos. As diferenças entre os dois grupos foram significantes para as três espécies. A análise com o emprego do teste exato de Fisher revelou significância $(P>0,99)$, com valores superiores ao crítico de 0,95 .

Da mesma forma procedeu-se quanto à análise da distribuição dos espécimens com positividade para sangue de ave e de mamíferos. Os dados obtidos encontram-se na Tabela 5. Verifica-se, inicialmente, que dos 
FORATTINI, O.P. et al. Hábitos alimentares, infecção natural e distribuição de triatomíneos domiciliados na região central do Brasil. Rev. Saúde públ., S. Paulo, 16:171-204, 1982.

1.133 com sangue no tubo intestinal, $70,5 \%$ revelaram a utilização de ave como fonte de alimentação sanguinea. Nesse particular destacaram-se $T$. sordida e $P$. megistus que mostraram $93,0 \%$ e $79,6 \%$, respectivamente, para esse tipo de alimento. Destacou-se a relativa baixa positividade para esse hospedeiro apresentada pelo $T$. infestans, e representada pelo coeficiente de $34,4 \%$.

Também procedeu-se à comparação dos números de espécimens positivos para ave, com uma ou mais fontes. Pôde-se verificar que, em relação a esse fator, a presença de sangue aviário sofreu variação apenas no que concerne ao $T$. infestans. No caso deste inseto, a comparação dos positivos para esse hospedeiro, dentre os que acusaram uma só fonte com os portadores da mesma positividade mas com mais de uma fonte, forneceu no teste exato de Fisher de $P=0,998$. Assim sendo, para exemplares dessa espécie que mostraram a presença de sangue de ave, a utilização desse hospedeiro foi significativamente maior dentre os que revelaram uma só fonte do que naqueles que apresentaram multiplicidade sanguínea. Por sua vez, esses representantes de $T$. infestans mostraram aumento na fre- quiência de utilização de sangue de outros hospedeiros, com a ocorrência de fontes múltiplas. Aliás, é de se notar que, em todos os casos, nesta espécie predominou a positividade para mamíferos.

Mobilidade - A ocorrência de possivel mobilidade espacial desses triatomíneos foi observada mediante a distribuição dos dados obtidos pelos ecótopos domiciliares e peridomiciliares. Nesse sentido, procurou-se observar a presença de tipos de sangue nessas duas situações, em especial modo o humano. $\mathrm{Na}$ Tabela 6 pode-se observar essa distribuição nas reaçōes positivas para as quais foi possível registrar essas informações. Verifica-se que em 927 reações houve $27,3 \%$ de positividade para homem, correspondendo a 253 resultados. Desses, $152(60,1 \%)$ foram obtidos no domicílio e $101(40,0 \%)$ no peridomicilio. Para as três espécies foi detectada a ocorrência de sangue humano nos ecótopos peridomiciliares, com percentuais de $22,2 \%$ para $P$. megistus e $T$. infestans e de $13,2 \%$ para $T$. sordida, do total respectivo de reaçoes positivas obtidas nesse ambiente. Todavia, a postividade geral para sangue humano no peridomicilio foi de $16,6 \%$ contra $83,3 \%$ para outros hospedeiros. As-

T A B E L A 2

Dados gerais sobre o número de fontes sanguíneas identificadas, em exemplares de triatomíneos da Região Central do Brasil.

\begin{tabular}{|c|c|c|c|c|c|c|c|c|}
\hline \multirow{2}{*}{$\begin{array}{l}\text { No de } \\
\text { fontes }\end{array}$} & \multicolumn{2}{|c|}{ P. megistus } & \multicolumn{2}{|c|}{ T. infestans } & \multicolumn{2}{|c|}{ T. sordida } & \multicolumn{2}{|c|}{ Total } \\
\hline & $N$ & $\%$ & $\mathrm{~N}$ & $\%$ & $\mathrm{~N}$ & $\%$ & $\mathrm{~N}$ & $\%$ \\
\hline Uma & 252 & 76,6 & 214 & 59,5 & 369 & 83,1 & 835 & 73,7 \\
\hline Duas & 61 & 18,5 & 125 & 34,7 & 66 & 14,9 & 252 & 22,2 \\
\hline Três & 15 & 4,6 & 21 & 5,8 & 7 & 1.6 & 43 & 3.8 \\
\hline Quatro & 1 & 0,3 & - & - & 2 & 0,4 & 3 & 0,3 \\
\hline Total & 329 & 100,0 & 360 & 100,0 & 444 & 100,0 & 1.133 & 100,0 \\
\hline
\end{tabular}



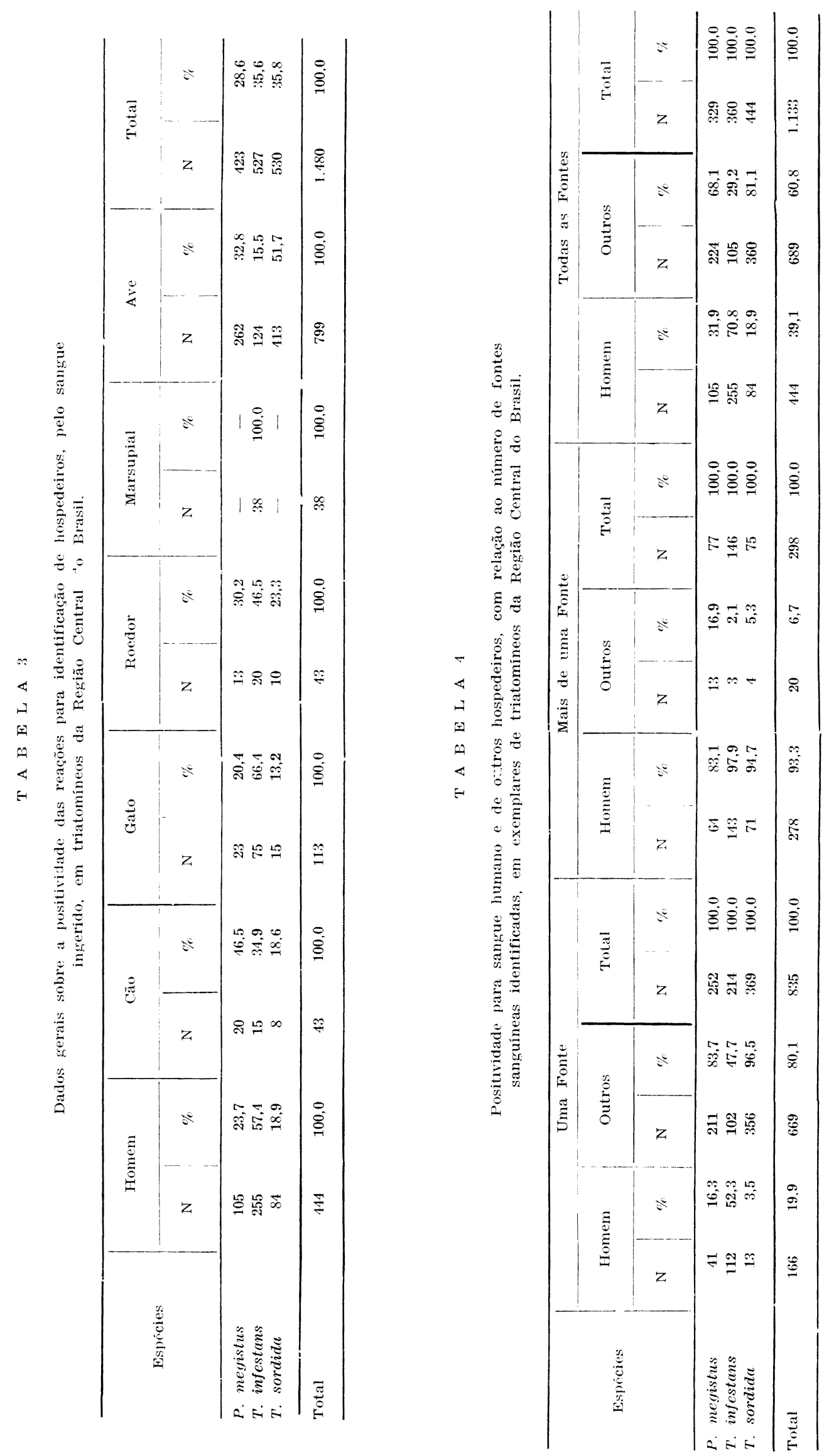

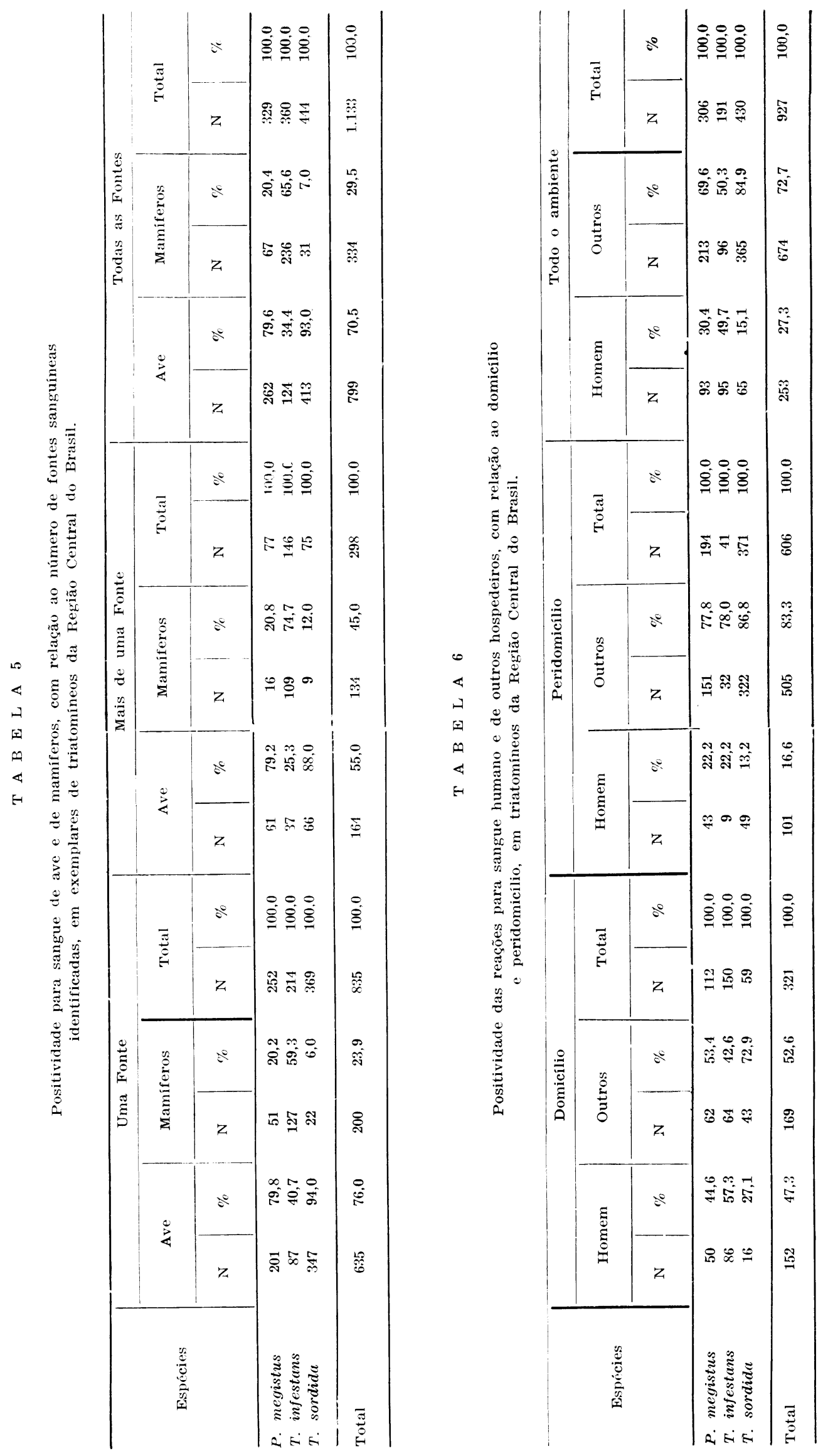
FORATTINI, O.P. et al. Hábitos alimentares, infeç̧ão natural e distribuição de triatomíneos domiciliados na região central do Brasil. Rev. Saúde públ., S. Paulo, 16:171-204, 1982.

sinale-se outrossim que, no domicilio, esses coeficientes foram de 47,3 e $52,6 \%$, respectivamente. Chama pois a atenção que elevada proporção das reações obtidas em triatomineos no meio domiciliar foram positivas para tipos de sangue que não o do homem. Por sua vez, a existência de reatividade para esse hospedeiro no peridomicílio foi apreciável. Não obstante, observando-se os dados referentes a $T$. sordida pôde-se notar a franca predominância de sangue de hospedeiros não humanos em ambos os tipos de ecótopos. Esse aspecto repetiu-se para $P$. megistus, embora não de maneira tão acentuada no domicilio. Por cutro lado, para $T$. infestans esse fato observou-se no peridomicilio, mas no ambiente domiciliar houve predomínio da presença do homem nas reações positivas alí obtidas.

Infecção natural - Já se referiu que o coeficiente geral para a presença de $T$. cruzi foi de $2,2 \%$, correspondendo a somente 69 exemplares dos 3.160 investigados. Para cada espécie, em relação ao respectivo total de examinados, a positividade foi a seguinte:

\begin{tabular}{lrl}
\multicolumn{1}{c}{ Espécie } & No & $\%$ \\
Panstrongylus megistus & 6 & 0,8 \\
Triatoma infestans & 60 & 4,4 \\
Triatoma sordida & 3 & 0,3 \\
Total & - & $-2,2$
\end{tabular}

Em relação à pesquisa de sangue ingerido, foi positiva apenas em 19 desses insetos. Representaram, pois, $1,7 \%$ dos 1.133 exemplares que, nas reações realizadas, acusaram a presença de conteúdo sanguineo no tubo intestinal. Na Tabela 7 pode-se cbservar os resultados relativos à ocorrência de infecção natural segundo o número de fontes sanguíneas. Verifica-se que, em conjunto, $1,6 \%$ dos triatomíneos que acusaram um só hospedeiro e $2,0 \%$ dos que revelaram mais de um mostraram a presença do parasito. Não houve pois dessemelhança apreciável, bem assim como para os coeficientes relativos a cada espécie. tendo a análise pelo teste exato de Fisher revelado a não significância das diferenças observadas. Distribuindo a presença da infecção natural com a de sangue humano, obteve-se os resultados apresentados na Tabela 8 . Da mesma forma, não se detectou diferença entre os coeficientes de infecção natural, com e sem sangue desse hospedeiro, tanto nos valores gerais como nos específicos. Muito provavelmente a ausência de significância nas diferenças obtidas decorreram do número reduzido de espécimens encontrados com infecção natural.

Distribuição biogeográfica - Com a finalidade de observar a distribuição biogeográfica dos hábitos alimentares, foram consideradas as regiones correspondentes às feições paisagisticas do cerrado, da floresta atlântica e das florestas de inclusão (Fig. 3). Os resultados relativos à positividade para sangue humano, e referentes aos 1.133 triatomineos que mostraram a presença de conteúdo sanguineo, acham-se expostos na Tabela 9. Foi possivel observar a presença de $P$. megistus e de $T$. infestans nas três regiōes, ao lado da ausência de $T$. sordida na floresta atlântica. No que concerne à positividade para homem, observou-se alguma variabilidade para as duas primeiras espécies. Quanto à terceira, sua presença praticamente limitou-se ao cerrado o que, neste caso particular, tornou dispensável a realização de testes para fins comparativos. No que diz respeito a $P$. megistus verificou-se que as distribuição geográfica obtida praticamente limitou essa espécie à floresta atlântica. E isso porque as áreas das florestas de inclusão, nas quais foi encontrada, restringiram-se ao leste e sudoeste do território do Estado de Minas Gerais, em boa parte incluído naquela paisagem ou apresentando caráter transicional entre ela e a do cerrado. Isso pode ser facilmente observado nos mapas das Figs. 2 e 4 . Isto posto, a aplicação do teste do qui quadrado para os coeficientes referentes a esse triatomineo e comparando, em conjunto, os das três regiões, somente revelou diferença significante em relação ao das florestas de inclusão, que se mostrou maior do que os 


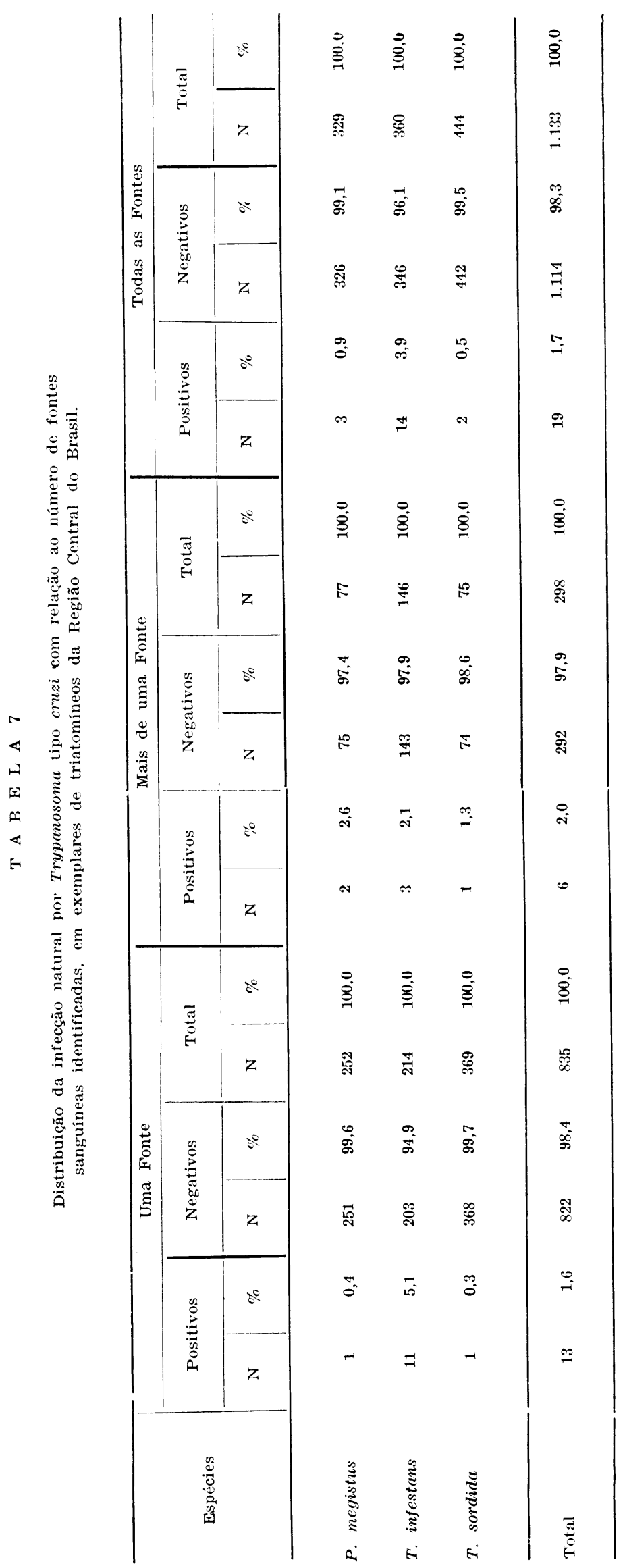


FORATTINI, O.P. et al. Hábitos alimentares, infecção natural e distribuição de triatomineos domiciliados na região central do Brasil, Rev. Saúde pübl., S. Paulo, 16:171-204, 1982.

outros dois. O valor observado foi de 26,12 enquanto é de 5,99 o referente ao nivel crítico a $5,0 \%$, com dois graus de liberdade. Por sua vez, não diferiram entre si os coeficientes obtidos para a floresta atlântica e para o cerrado no teste exato de Fisher ( $P .=0,82$ para valor critico de 0,95 ). Contudo, levando em consideração as ponderações acima expostas, procedeu-se à comparação do coeficiente relativo aos dados, em conjunto, das duas feiçōes paisagísticas florestais $(38,8 \%)$ com o do cerrado $(21,8 \%)$. A aplicação do mesmo teste de Fisher resultou em valor de $P>0,99$, revelando pois diferença significante entre os dois. Quanto aos dados referentes a $T$. infestans, a comparação das três regiōes pelo teste do qui quadrado revelou que os coeficientes relativos à floresta atlântica $e$ floresta de inclusão são significativamente maiores do que o do cerrado. $O$ valor observado foi de 29,11 para o mesmo nivel crítico supracitado. Por sua vez, também não diferiram entre si, no teste exato de Fisher, os coeficientes obtidos para a floresta atlântica e as de inclusão $(P:=0,48)$. Todavia, considerou-se que a ocorrência deste triatomineo na primeira dessas duas regiões limitou-se a áreas do sudoeste do Estado de Mato Grosso do Sul, de freqüente caráter transicional com o cerrado. Por sua vez, ao contrário de $P$. megistus, foi encontrado em manchas florestadas inclusas no cerrado e mais afastadas da floresta atlântica, ou seja, no assim chamado "Mato Grosso de Goiás". Tais aspectos podem ser observados nos mapas das Figs. 2 e 5. Em vista disso, comparou-se igualmente o coeficiente dos dados, em conjunto, das duas feiçōes paisagísticas florestais $(85,4 \%)$ com o do cerrado $(59,4 \%)$. A aplicação do teste de Fisher resultou em valor de $P>0,99$, implicando pois significância para a diferença observada entre os dois.

Assim sendo, tanto para $P$. megistus como para $T$. infestans, dentre os espécimens que acusaram conteúdo intestinal sanguíneo, a distribuição geográfica dos coeficientes de positividade para sangue humano variou de maneira significante, de acordo com as regiōes consideradas. Para ambas essas populações, os valores foram maiores nas áreas florestadas, atlântica e de inclusão, do que nas do cerrado. Em se tratando da primeira dessas espécies, a possível maior antropofilia que se observou nas regiões de mata acompanha a distribuição eminentemente florestal desse triatomineo. O mapa da Fig. 7 fornece idéia dessa distribuição.

Outras espécies - Como se mencionou, além das três espécies que predominaramı

T A B E L A 8

Distribuição da infeção natural por Trypanosoma tipo cruzi com relação à presença de sangue humano, em exemplares de triatomíneos da Região Central do Brasil.

\begin{tabular}{|c|c|c|c|c|c|c|c|c|c|}
\hline \multirow{2}{*}{ Espécies } & \multicolumn{3}{|c|}{ Com sangue humano } & \multicolumn{3}{|c|}{ Sem sangue humano } & \multicolumn{3}{|c|}{ Total } \\
\hline & $\mathrm{N}$ & $\%$ & $\begin{array}{r}\text { Total de } \\
\text { examinados }\end{array}$ & $\mathrm{N}$ & $\%$ & $\begin{array}{c}\text { Total de } \\
\text { examinados }\end{array}$ & $N$ & $\%$ & $\begin{array}{c}\text { Total de } \\
\text { examinados }\end{array}$ \\
\hline$P$. megistus & 1 & 1,0 & 105 & 5 & 0,8 & 636 & 6 & 0,8 & 741 \\
\hline T. infestans & 9 & 3,5 & 255 & 51 & 4,5 & 1.120 & 60 & 4,4 & 1.375 \\
\hline T. sordida & 2 & 2,4 & 84 & 1 & 0,1 & 960 & 3 & 0,3 & 1.044 \\
\hline Total & 12 & 2,7 & 444 & 57 & 2.0 & 2.716 & 69 & 2,2 & 3.160 \\
\hline
\end{tabular}




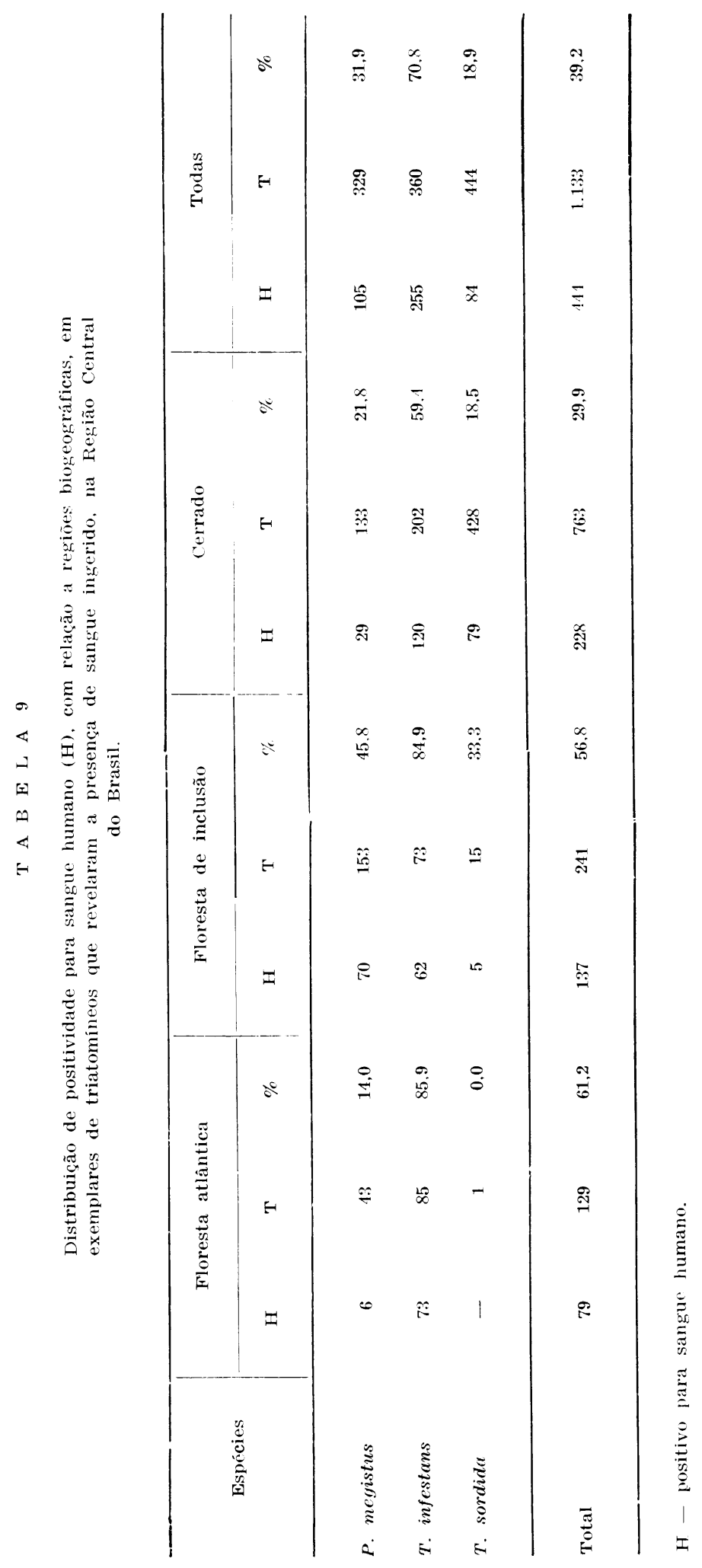


FORATTINI, O.P. et al. Hábitos alimentares, infeç̧ão natural e distribuição de triatomíneos domiciliados na regiăo central do Brasil. Rev. Saúde públ., S. Paulo, 16:171-204, 1982.

no material coletado, foi possivel encontrar outras, cujos representantes totalizaram 26 exemplares. Foram as seguintes (Fig. 5): Rhodnius nasutus $(1 \mathrm{n})$ - Mun. Montes Claros, Estado de Minas Gerais (V. 1980). Rhodnius neglectus ( 1 to $3 \mathrm{nn}$ ) - Mun. Itaberai, $1 \mathrm{n}$, Est. Goiás (X.1975); Mun. Itaporanga, $1 \mathrm{n}$, no peridomicilio, Est. Goiás (XI.1975); Mun. Perdizes, $1 \mathrm{n}$, no peridomicilio, Est. Minas Gerais (III.1978); Mun. Montes Claros, $1 \hat{\delta}$, Est. Minas Gerais (V.1980).
Triatoma brasiliensis ( 1 \& 4 ô $\&$ $1 \mathrm{n}$ ) Mun. Barão de Grajaú, 3 ô $\delta$, no domicílio, Est. Maranhão (IV.1978); Mun. Loreto, 1 q 1 \& 1 n, Est. Maranhão (VII.1978).

Triatoma pseudomaculata $(4$ 우 2 \& $\delta$ $9 \mathrm{nn})-$ Mun. Itaberai, 2 \% 2 nn, Est. Goiás (X.1975); Mun. Petrolina, 4 nn, Est. Goiás (X.1975); Mun. S. Felix de Balsas, $2 \mathrm{nn}, \quad$ no peridomicílio, Est. Maranhão (XII. 1980) ; Mun. S. João dos Patos, 2 ㅇ 2 \&ิ \& $1 \mathrm{n}$, no peridomicilio, Est. Maranhão (V.1980).

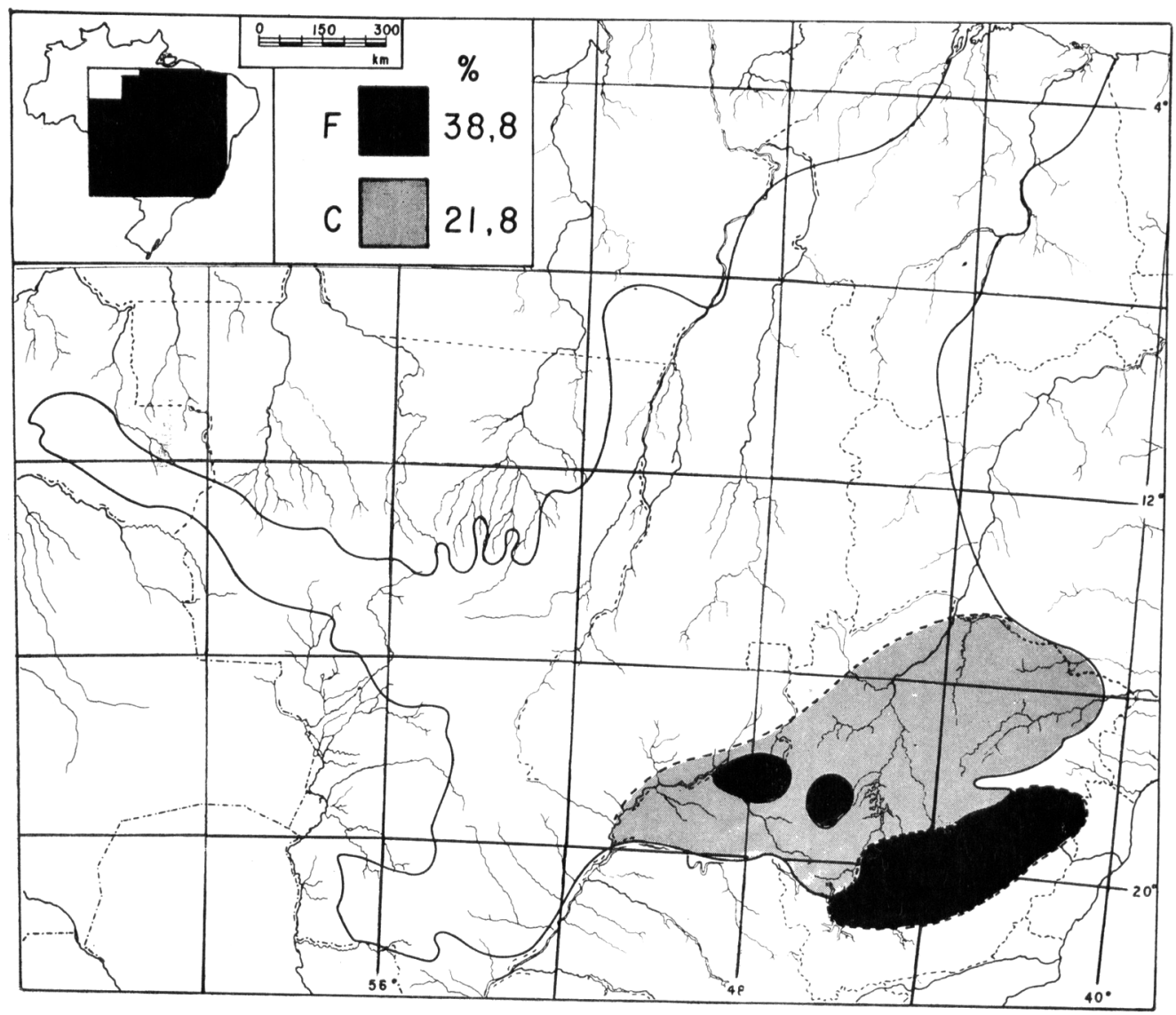

Fig. 7 - Positividade para sangue humano, encontrada em Panstrongylus megistus, na regiăo central do Brasil. Distribuição biogeográfica dos coeficientes gerais, de acordo com as feiç̋es paisagísticas. $F$ - floresta atlântica e florestas de inclusão: $38,8 \%$; $C$ - cerrado: $21.8 \%$. 
FORATTINI, O.P. et al. Hábitos alimentares, infecçăo natural e distribuição de triatomineos domiciliados na região central do Brasil. Kev. Saúde puibl., S. Paulo, 16:171-204, 1982.

Somente foi encontrada infecção natural em três exemplares de $T$. pseudomaculata coletados em Petrolina, Estado de Goiás. Quanto à presença de sangue ingerido obteve-se positividade apenas para sangue de ave. Essa reatividade correspondeu a cinco espécimens, assim distribuídos, um de $R$. nasutus (Montes Claros, Est. Minas Gerais), um de $R$. neglectus (Perdizes, Est. Minas Gerais) e três de $T$. pseudomaculata (um de S. Felix de Balsas e dois de $S$. João dos Patos, Est. Maranhão).

\section{COMENTARIOS}

Os dados acima expostos resultaran de coletas no ambiente domiciliar da região central do Brasil, no período de 1975 a 1980. Foram abrangidos 198 municipios distribuidos por quatro Estados e três feições paisagisticas principais. A exemplo do que foi upresentado em publicação anterior, com essa amostra pretendeu-se conseguir informações sobre hábitos alimentares e infeç̧ão natural por Trypanosoma tipo cruzi. Ao lado disso, objetivou-se obter dados a respeito da distribuição geográfica e aspectos biogeográficos que permitissem apreciação do papel desempenhado pelas populações triatomineas domiciliadas, na transmissão regional da tripanossomíase americana (Forattini e col.16, 1981).

Quanto à presença de sangue no conteúdo intestinal, o coeficiente geral foi de $35,9 \%$ dos espécimens examinados, ou seja, correspondendo a 1.133 triatomíneos. De maneira constante, a maioria revelou a ocorrência de um só hospedeiro, e isso tanto no aspecto genérico como no concernente a cada espécie (Tábela 2). Por sua vez, a multiplicidade sanguinea foi detectada em $36,3 \%$ dos insetos que reagiram positivamente às provas efetuadas. A presença de fontes múltiplas, na maioria dos casos, implicou a ocorrência de dois hospedeiros, perfazendo $84,6 \%$ do total de espécimens que acusaram mais de um tipo de sangue. De qualquer modo, a frequêencia mais elevada de multiplicidade sanguinea foi obser- vada em $T$. infestans, com $40,5 \%$ enquanto nas outras duas espécies, $P$. megisttus e $T$. sordida, esses coeficientees foram de 23,4 e $16,9 \%$, respectivamente. Assim sendo, pôde-se observar a ocorrência de apreciável mobilidade alimentar, em especial modo no que respeita ao primeiro desses triatomineos. $\mathrm{E}$ isso concorda com aspecto análogo observado em outras regiões, tanto do Brasil como da Argentina, onde essa espécie revelou coeficientes de 34,7 e $35,6 \%$ de alimentações múltiplas (Minter 2s, 1976). Mesmo no que concerne às outras duas espécies, a presença de multiplicidade sanguinea foi digna de nota, sobretudo em $P$. megistus. Em $T$. sordida foi obtido menor coeficiente, o que poderia indicar mobilidade alimentar mais baixa, mesmo assim, porém, bastante apreciável. Esses dados foram pouco inferiores aos que, em trabalho anterior, foram registrados para essas mesmas espécies na região nordeste (Forattini e col.16, 1981). Contudo indicam, da mesma maneira, a possibilidade de considerável freqüência na troca de hospedeiros utilizados nos repastos sanguíneos.

Considerando-se essa mobilidade em relação aos vários tipos de fontes testadas observa-se que, da totalidade de reações obtidas, $54,0 \%$ o foram para ave, $30,0 \%$ para homem e os restantes $16,0 \%$ para os outros hospedeiros. Esses resultados concordam com os encontrados no nordeste, sem alteração sensivel do quadro geral. A observação dos dados expostos na Tabela 3 permite evidenciar nitida preponderância de sangue de mamiferos $(76,5 \%)$ em $T$. infestans, ao passo que nas outras duas espécies houve maioria para sangue de ave. Neste particular, destacaram-se os resultados obtidos em $T$. sordida, onde o quadro geral para hospedeiro aviário $(77,9 \%)$ foi equivalente ao de para mamifero naquele triatomíneo. A interpretação desses resultados, à luz dos conhecimentos disponiveis, permite verificar a uniformidade de comportamento por parte de $T$. infestans, ao lado da variabilidade apresentada pelos outros dois. Com efeito, em relação àquele nota-se que, em 
FORATTINI, O.P. et al. Hábitos alimentares, infecção natural e distribuiçăo de triatomineos domiciliados na regiăo central do Brasil. Rev. Saúde públ., S. Paulo, 16:171-204, 1982.

que pese o ecletismo alimentar demonstrado, foi marcante a positividade para mamiferos em geral e para o homem em particular. A participação deste último hospedeiro, no total de reações para essa espécie que revelaram sangue ingerido, foi de $48,4 \%$, além de ter contribuído com $57,4 \%$ do total geral de reações para sangue humano. Esse quadro apresenta-se razoavelmente uniforme, quando se consideram outras pesquisas levadas a efeito com esse triatomineo, e pode ser atribuído à elevada domiciliação de que é dotado (Barretto 5 1968; Minter 28 1976; Knierim e col.22 1976; Marsden e col..27 1979; Schofield ${ }^{36}$ 1980; Forattini e col.16 1981). No que respeita a $T$. sordida, sua contribuição foi de cerca de $52,0 \%$ do total de posittividade para sangue de ave, o que concorda com ulgumas observaçōes em outras regiōes meridionais do Brasil (Forattini e col.12 1971; Rocha e Silva e col. ${ }^{32}$ 1977). Todavia, esse aspecto não é constante pois com frequiência tem-se registrado variaçōes apreciáveis, com a associação dessa espécie a sangue de mamiferos (Barretto ${ }^{3}$ 1971; Forattini e col.16 1981). A explicação dessas discrepâncias possivelmente reside na ocupação do peridomicílio, por parte desse triatomíneo, com a disponibilidade de hospedeiros diversos representados por animais domésticos ali abrigados. As sistemáticas campanhas de controle $\mathrm{e}$ a vigilância subseqüente têm limitado esse inseto aos anexos das habitações humanas, os quais, a mais das vezes, servem de abrigo a aves. $\mathrm{Da}$ mesma forma, os achados relativos a $P$. megistus mostraram marcante presença do hospedeiro aviário correspondendo a cerca de $33,0 \%$ da positividade total obtida para esse tipo de sangue. Do conjunto de reações conseguidas nessa espécie de triatomíneo, o percentual correspondente a ave $(32,8 \%)$ foi pouco diferente daquele relativo aos vários mamiferos, incluindo o homem $(38,1 \%)$. Assim sendo, não se observou a preponderância por parte desses últimos hospedeiros que se verificou quando das investigações realizadas na região nordeste. Esse inseto contribuiu com cerca de $24,0 \%$ das reações para sangue humano, e predominou apenas naquelas positivas para cão. Contudo, em relação a este último, é de se ressalvar o reduzido número de reaçōes obtidas. A explicação para esse quadro deverá ser encontrada, muito provavelmente, nos mesmos fatores supracitados e relacionados com o controle antitriatomineo a que está sendo submetida a região central do Brasil, principalmente o Estado de Minas Gerais, e que data de tempo relativamente bem anterior ao das demais regiões (Marques ${ }^{26}, 1979$ ).

Objetivando detectar possiveis preferências na escolha de determinados hospedeiros, os dados foram distribuidos por número e por alguns tipos de fontes, como mostram as Tabelas 4 e 5 . Observou-se, assim, a positividade para sangue humano destacando-se, nesse particular, o $T$. infestans com cerca de $71,0 \%$ dos correspondentes espécimens portadores de conteúdo intestinal sanguíneo. Por sua vez, em $P$. megistus e em $T$. sordida esse coeficiente foi bem inferior, correspondendo a cerca de $32,0 \%$ para o primeiro e a $19,0 \%$ para o segundo. As diferenças registradas em relação à presença de um ou mais tipos de sangue foram significantes para as três espécies, indicando que a positividade para o hospedeiro humano mostra tendência ao aumento com a multiplicidade de fontes utilizadas. Em relação a $T$. infestans esse aspecto discordou do observado na região nordeste onde 0 aumento da positividade para homem não sofreu influência da multiplicidade de hospedeiros. E de se invocar, pois, os fatores já mencionados relativos à existência de campanha de controle domiciliar mais antiga, condicionando probabilidade de recurso do triatomineo a outras fontes sanguineas lançando mão assim do caráter oportunista da escolha para 0 repasto sanguíneo (Schofield ${ }^{35}$, 1979). Por sua vez, procedendo-se a comparação análoga com a focalização do sangue de ave, obteve-se feição inversa no mesmo $T$. infestans, como se pode observar na Tabela 5. Com efeito, nesse triatomíneo, a positividade para o hospedeiro aviário não aumentou com o número de fontes, ou seja, foi significativamente maior nos espé- 
FORATTINI, O.P. et al. Hábitos alimentares, infecção natural e distribuição de triatomíneos domiciliados na região central do Brasil. Revev. Saúde públ., S. Paulo, 16:171-204, 1982.

cimens que revelaram apenas um tipo de sangue ingerido. O mesmo nāo se observou quanto a $P$. megistus e $T$. sordida cuja reatividade para ave não apresentou modificação com o número de fontes. Ressalte-se que, em tal possível ornitofilia, esses dois triatomineos andaram relativamente próximos com cerca de, respectivamente, 80,0 e $93,0 \%$ dos correspondentes representantes portadores de sangue ingerido. $E$ de se considerar a hematofagia sobre aves domésticas como bom indício de colonização peridomiciliar, pelo menos em parte. Dessa forma, os achados supracitados reforçam a hipótese de pressão seletiva regional exercida pelas atividades de controle, decorrentes de campanhas sistemáticas visando o meio domiciliar. Como resultado, é lícito admitir que essas populações triatomíneas, tenham tendido a se acantonarem em anexos que constituem, no seu conjunto, o ambiente peridomiciliar.

Em resumo, nesta região central do Brasil, ao que tudo indica, mantém-se a apreciável antropofilia do $T$. infestans, embora esse inseto revele ecletismo que lhe permite adaptar-se ao convivio com outros hospedeiros. Este último aspecto tornou-se mais acentuado em relação a $P$. megistus que demonstrou considerável ornitofilia. Quanto a $T$. sordida sua maior tendência para sugar aves pareceu bastante evidente nestas observações, ao lado de papel discreto na procura de sangue de mamíferos.

Os resultados expostos na Tabela 6 mostram a presença de espécimens com sangue humano, no peridomicilio. Obviamente esse fato traduz mobilidade espacial. Contudo convém considerar que somente $9,5 \%$ das reações de $T$. infestans com essa positividade 0 foram nesse ambiente, enquanto esses coeficientes para $P$. megistus e $T$. sordida foram de cercá de 46,0 e $75,0 \%$, respectivamente. Parece lógico supor que o primeiro desses triatomíneos apresenta pouca tendência ao abandono do domicílio, somente fazendo-o sob pressões seletivas como as já mencionadas campanhas de controle. Quanto aos demais, o deslocamento é bastante evidente, com a possibilidade de considerável número de exemplares poderem ser encontrados fora das habitaçóes após a execução do repasto sanguíneo. Quanto à presença de reatividade para outros hospedeiros, no domicilio, as condsiderações não podem ser estritamente análogas, uma vez que comumente a habitação humana constitui também abrigo para diversos animais domésticos. Contudo, serve para evidenciar as possibilidades de intercâmbio entre hospedeiros diversos nesse ambiente. De resto, essas observaçōes sobre mobilidade espacial confirmam as efetuadas em outras regiões (Forattini e col.13,14,15,16 1973, 1975, 1977, 1981).

O coeficientee de infecção natural foi baixo, correspondendo ao valor geral de $2,2 \%$, descendo para $1,7 \%$ ao se considerar apenas o número de espécimens que acusaram conteúdo sanguíneo no tubo intestinal. Tanto a distribuição dessa positividade pelo número de fontes (Tabela 7) como pela presença de sangue humano (Tabela 8 ), não revelou diferenças significantes para qualquer das três espécies triatomíneas. Em outras palavras, os dados obtidos não permitiram detectar qualquer influência do número de hospedeiros e da presença do homem, na infecção natural revelada por esses triatomineos. Tais achados confirmam os obtidos na região nordeste. Todavia, é de se considerar o pequeno número de espécimens infectados nas presentes observações, o que possivelmente possa ter influído para a falta de significância nas diferenças registradas.

A distribuição geográfica observada mostrou os aspectos representados nos mapas das Figs. 4 a 6 . Inicialmente pode-se observar certa semelhança na distribuição apresentada por $T$. infestans e $T$. sordida, estando este último limitado à feição paisagística do cerrado (Figs. 5 e 6 ). A presença dos dois triatomineos nas florestas de inclusão, torna-se particularmente significativo ao se considerar a grande mancha situada no sul do território goiano e conhecida como "Mato Grosso de Goiás". Sendo área sujeita a 
FORATTINI, O.P. et al. Hábitos alimentares, infeç̧ăo natural e distribuição de triatomíneos domiciliados na região central do Brasil. Rev. Saúde públ., S. Paulo, 16:171-204, 1982.

profundas transformaçōes de origem antrópica, face à exploração agropecuária, é de se admitir que ambas as espécies ali penetraram mediante invasão propiciada pela atividade humana. Tais consideraçōes vêm ao encontro das hipóteses levantadas sobre as direções de dispersão desses triatomineos a partir de seus possiveis centros de endemismo, situados na Bolivia e no Brasil Central, respectivamente. Quanto ao $P$. megistus, a sua distribuição apresenta nítida influência das áreas do domínio tropical atlântico, representado pelas suas florestas. E a tal ponto de não ter sido encontrado nas manchas de matas de inclusão mais afastadas dessa feição paisagistica (Fig. 4). Sua presença no cerrado representa, muito provavelmente, processo secundário de dispersão para as áreas abertas, à semelhança do observado na caatinga da região nordeste. Inclua-se, neste mesmo aspecto, o seu encontro no Estado do Maranhão, no extremo norte da região aqui focalizada (Forattini ${ }^{11}, 1980$ ). A comparação desses quadros com o dos aspectos paisagísticos biogeográficos representado na Fig. 2 permite o estabelecimento dessas associações e das hipóteses supracitadas.

Ao se distribuir, pelas várias regiões paisagisticas, os resultados da positividade em relação a sangue humano, obteve-se os dados apresentados na Tabela 9. Tomando-se em conjunto os dados correspondentes às regiões florestadas, tanto atlântica como de inclusão, e comparando-os com os do cerrado, obteve-se diferenças significantes, com valores maiores para os primeiros do que para os segundos, no que concerne a T. infestans e $P$. megistus. Deixando de considerar $T$. sordida, dado o ser espécie característica do cerrado, e $T$. infestans, em virtude da elevada domiciliação que empresta predominante caráter antrópico ao seu mecanismo dispersivo, restou observar a distribuição biogeográfica da alimentação de $P$. megistus em sángue humano, como está representada no mapa da Fig. 7. A menor antropofilia observada para esse triatomineo no domínio dos cerrados
$(21,8 \%)$, em comparação com a verificada nas áreas florestadas $(38,8 \%)$, poderá ser explicada pela sua mais recente introdução naquela região. É sabido que as áreas cobertas por florestas têm sido as mais visadas pelo processo de exploração agropecuária, ensejando convivência mais antiga entre o triatomíneo e o homem. Por sua vez, as regiões dos cerrados, sobre terem sido colonizadas irregularmente, só em tempos recentes têm sido objeto de atenções objetivando sua exploração econômica. Dessa maneira, ali as populações de $P$. megistus tendem a manter maior ecletismo alimentar, para o qual também contribuem as campanhas de controle encetadas há mais tempo nessas regiões do que nas outras. De qualquer maneira, esse aspecto de distribuição geográfica vem ao encontro da hipótese que associa a instalação de áreas abertas ao estimulo para a domiciliação triatomínea (Forattini 11, 1980).

Em resumo, comparando-se investigação com a realizada na região nordeste (Forattini e col. ${ }^{16}, 1981$ ) verifica-se não ter havido desproporção no que concerne ao número de municipios e localidades pesquisadas. Eis que, pará 238 e 2.114 , o que dá em média cerca de 9,0 localidades por área municipal nordestina, obteve-se 198 e 1.513 , o que fornece a média de 7,6 por município da região central. Não obstante, o número de triatomineos coletados foi substancialmente menor, com a cifra de 3.160 exemplares contrá 15.342 obtidos no nordeste. Tendo sido semelhantes os processos utilizados, resta ponderar que tal diversidade se deva a outros fatores. Entre eles, ressalta $o$ fato da região central do Brasil ser das que há mais tempo se encontra sujeita a campanhas continuadas de controle e de vigilância. Por sua vez, a menor riqueza faunistica limitou praticamente a duas espécies, ou seja, $P$. megistus e $T$. sordida como sendo as que se encontram atualmente em processo mais recente de domiciliação, se comparadas com a terceira, $T$. infestans, cuja adaptação à habitação humana é mais antiga e mais acentuada. 
FORATTINI, O.P. et al. Hábitos alimentares, infecção natural e distribuiçăo de triatomíneos domiciliados na região central, do Brasil. Rev. Saúde públ., S. Paulo, 16:171-204, 1982.

\section{CONCLUSOES}

1. A mobilidade alimentar observada foi apreciável, embora $T$. sordida tenha revelado menor diversidade em fontes diversas.

2. Tornou-se visivel maior tendência antropófila por parte de $T$. infestans, e menor em $P$. megistus e $T$. sordida. Observou-se preponderância para aves por parte deste último, enquanto apreciável grau de ornitofilia foi também detectado em $P$. megistus.

3. A mobilidade espacial, detectada pela presença de sangue humano em exemplares coletados no peridomicilio, foi mais evidente em $P$. megistus e $T$. sordida. Essa exofilia foi sensivelmente menor em $T$. infestans.

4. Pela distribuição geográfica obtida observa-se 0 caráter invasivo de $T$. infestans e $T$. sordida para regiões florestadas sujeita à exploração agropecurária. Quanto a $P$. megistus mostrou-se invasivo em relação ao cerrado.

5. A antropofilia de $P$. megistus mostrou-se inferior no cerrado do que nas áreas florestadas. A explicação pođerá ser encontrada na mais prolongada convivència com o homem que o triatomíneo tem exercido nessas últimas áreas.

6. Os dados biogeográficos concordam com a hipótese de que os espaços abertos estimulam a domiciliação triatonínea.

7. Considerando os dados obtidos, as populações triatomíneas domiciliadas nessa região podem ser assim classificadas:

a) Invasiva dispersada pelo homem, a partir das regiões sul-ocidentais:

$$
\text { T. infestans }
$$

b) Invasiva, em relação ao cerrado, dispersada pelo homem, a partir da região oriental (atlântica):

\section{P. megistus}

c) Invasiva, em relação a floresta, tendo no cerrado seu centro de dispersão:

\section{T. sordida}

d) Domiciliada, antropófila, com alguma tendência para o peridomicílio:

\section{T. infestans}

e) Com tendência à domiciliação com ecletismo alimentar ornitófilo, e invasão do peridomicilio:

\section{P. megistus \\ $T$. sordida}

8. Em decorrência, o papel principal na transmissão da tripanossomíase americana, nessa região, cabe ao $T$. infestans. Segue-lhe, em importância, $0 \quad P$. megistus. Quanto ao $T$. sordida, ao que tudo indica, sua atuação nesse sentido seria apenas secundária.

\section{AGRADECIMENTOS}

Ás Diretorias regionais da SUCAM nas pessoas dos Doutores Benedito de Souza, Carlos Alberto Silveira Matos, Edward Ferreira de Carvalho, Edyr Pedroso Daubian, Ernani Wilson Bezerra Carneiro, Francisco Alcântara Lobo, Hamilto Ramalho, Horácio Velloso da Silveira Neto, Ivan Frota da Silveira, Joaquim Rodrigues Cavalcanti, Nelson Oscar Schuffner, Paulo de Araújo Magalhães e Raimundo Costa Damasceno, pela diligência no envio do material que serviu a estas pesquisas. 
FORATTINI, O.P. et al. Hábitos alimentares, infeç̧ão natural e distribuição de triatomíneos domicillados na regiāo central do Brasil. Rev. Saúde públ., S. Paulo, 16:171-204, 1982.

FORATTINI, O, P. et al. [Feeding habits, natural infection and distribution of domiciliary triatominae bugs in the central region of Brazil]. Hev. Saúde públ., S. Paulo, 16:171-204, 1982.

ABSTRACT: This is the presentation of data obtained by a study carried out in central Brazil, where the biogeographical characteristics include the "cerrados" (savannah), ample strips of transitional vegetation, and forests. These include the Atlantic tropical forest and the larger forested areas. From 1975 to 1980 , a total of 3,160 bugs collected in domiciliar environments were examined to discover the blood feeding habits and the natural infection by Trypanosoma of the cruzi type. Methods were the same as those described in a previous paper. In order of frequency, the species found were: Triatoma infestans $(43.5 \%)$, T. sordida $(33.0 \%)$ and Panstrongylus megistus $(23.5 \%)$, and some other rare ones. Blood was detected in $35.9 \%$ and the infection rate was $2.2 \%$ of the total specimens examined. Feeding mobility was observed, and the general blood containing rates were $54.0 \%$ from birds and $30.0 \%$ from humans. High evel of anthropophily was observed for $\mathbf{T}$. infestans, and good degree of ornitophily was detected for $\mathbf{T}$. sordida. For P. megistus considerable ornitophily was found too, but with good levels from mammal hosts. The presence of human blood in specimens collected in peridomiciliar dwelling places indicated frequent spacial morbility, specially for $\mathbf{P}$. megistus and $\mathbf{T}$. sordida. Geographical distribution confirmed the autochthonous pattern of $\mathbf{T}$. sordida in the "cerrado" and of $\mathbf{P}$. megistus in the Atlantic tropical forest. They become invasive to other biogeographical system from theee regions. $\mathbf{T}$. infestans showed invasive character for both areas, as a results of human influence. Results permit the conclusion that, in the regional epidemiological transmission of South American trypanosomiasis, $\mathbf{T}$. infestans play the most important role, followed by $\mathbf{P}$. megistus. Depending on several factors, $\boldsymbol{T}$. sordida may become a potential risk for infestation dwellings. Routine control through the application of domiciliary chemicals will break transmission. However, at least in the peridomiciliary environment, reinfestation will continue. mainly by $\mathbf{P}$. megistus and $\mathbf{T}$. sordida. This will be due to natural foci supplied by the human environment, demanding greater efforts in epidemiological surveillance and in its increased efficiency by research development.

UNITERMS: Trypanosomiasis, South American. Triatominae, Brazil central region. Triatominae, food habits. Triatominae, natural infection. Triatominae, domiciliation.

\section{REFERENCIAS RIBLIOGRAFICAS}

1. AB'SABER, A.N. A organização natural das paisagens inter e subtropicais brasileiras. In: Ferri, M.G., coord, - III simpósio sobre o cerrado. São Paulo, Ed. Edgard Blücher/EDUSP, 1971, p. 1-14.

2. AB'SABER, A.N. Potencialidades paisagisticas brasileiras. São Paulo, Instituto de Geografia da USP, 1977. (Série Geomorfologia, 55).

3. ALONSO, M.T.A., Vegetação. In: Fundação IBGE. Geografia do Brasil: regiāo sudeste. Rio de Janeiro, 1977. ₹. 3, p. 91-118.
4. AZEVEDO, L.G. de Vegetação. In: Conselho Regional de Geografia. Atlas do Brasil (geral e regional). Rio de Janeiro, 1959. p. 58.

5. BARRETTO, M.P. Estudos sobre reservutórios e vectores silvestres do "Trypanosoma cruzi". XXXI - observações sôbre a associação entre reservatórios e vectores, com especial referência à região nordeste do estado de São Paulo. Rev. bras. Biol., 28:481-94, 1968.

6. BARRETTO. M.P. Estudos sobre reservatórios e vectores silvestres do Trypanosoma cruzi. XLV - Inquérito prell- 
FORATTINI, O.P. et al. Hábitos alimentares, infecção natural e distribuiçăo de triatomíneos domiciliados na região central do Brasil. Rev. Saúde públ., S. Paulo, 16:171-204, 1982.

minar sobre triatomineos silvestres nc sul do Estado de Mato Grosso, Brasil (Hemiptera, Reduviidae). Rev, bras. Biol., 31 :225-33, 1971.

7. BROWN Jr., K.S. Ecologia geográfica e evolução nas florestas neotropicais. Campinas, 1979. [Tese - Universidade Estadual de Campinas]

8. FAISSOL, S. O problema do desenvolvimento agrícola do sudeste do planalto central do Brasil. Rev. bras. Geogr., 19:3-66, 1957.

9. FERRI, M.G., coord. IV simposio sobre o cerrado. São Paulo, EDUSP/Livr. Itatiaia, 1977.

10. FIALHO, O. Aspectos do revestimento florístico do Maranhão. Rev. Geogr. Hist, São Luiz, 4:115-25, 1953.

11. FORATtinI, O.P. Biogeografia, origem e distribuição da domicilização de triatomineos no Brasil. Rev. Saúde puibl., $\mathrm{s}$. Paulo, 14:265-99, 1980.

12. FORATTINI, O.P. et al. Aspectos ecológicos da tripanossomose americana. III - Dispersão local de triatomíneos com especial referência ao Triatoma sordida. Rev. Saúde públ., S. Paulo, 5:193-205, 1971.

13. FORATtiNi, O.P. et al. Aspectos ecológicos da tripanossomose americana. V -- Observações sobre a colonização espontânea de triatomíneos silvestres em ecótopos artificiais, com especial referência ao Triatoma sordida. Rev. Saúde publ., S. Paulo, 7:219-39, 1973

14. FORATTINI, O.P. et al. Aspectos ecológicos da tripanossomíase americana. VII - Permanência e mobilidade de Triatoma sordida em relação aos ecótopos artificiais. Rev. Saúde públ., S. Paulo, 9:467-76, 1975.

15. FORATTINI, O.P. et al. Aspectos ecológicos da tripanossomíase americana. IX - Variação e mobilidade de Pans. trongylus megistus em ecótopos artificiais. Rev. Saride pübl., S. Paulo. $11: 199-213,1977$.

16. FORATTINI, O.P. et al. Hábitos alimentares, infecção natural e distribuição de triatomíneos domiciliados na região nordeste do Brasil. Rev. Sanide puibl., S. Paulo, 15:113-64, 1981.
17. GALVÃO, R. Introdução ao conhecimento da área maranhense abrangida pelo plano de valorização econômica da Amazônia. Rev. bras. Geogr., 17:239-96, 1955.

18. HUECK, K. Sôbre a origem dos campos cerrados do Brasil e algumas novas observações no seu limite meriđional. Rev. bras. Geogr., 19:67-82, 1957.

19. HUECK, K. As florestas da America do Sul, São Paulo, Editora Univ. Brasilia/ Ed. Poligono, 1972.

20. HUECK, K. \& SEIBERT, P. Vegetationskarte von sudamerika. Stuttgart, Gustav Fischer Verlag, 1972.

21. KoEpPeN, W. Climatologia. México, Fondo de Cultura Economica, 1948.

22. KNIERIM, F. et al. Estudio preliminar sobre la fuente de alimentación de Triatoma infestans y Triatoma spinolai mediante la reacción de doble difusión en gel. Bol. chil. Parasit., 31:34-6, 1976.

23. KUHLMANN, $E$. Os grandes traços da fitogeografia do Brasil. Bol. geogr. $11: 618-28,1953$.

24. KUHLMANN, E. Vegeteção. In: Fundação IBGE. Geografia do Brasil: regiåo nordeste. Rio de Janeiro, 1977. v. 2. p. 85-110.

25. MAGALHAES, G.M. Sobre os cerrados de Minas Gerais. In: Labourian, L.G. ed. Segundo simpósio sobre o cerrado. An. Acad. bras, Cienc., 38(Supl.):59-71. 1966.

26. MARQUES, A.C. Controle de vetores da doença de Chagas: experiência do Ministério da Saúde, Brasil. [Apresentado ao Congresso Internacional de Doença de Chagas, Rio de Janeiro, 1979]

27. MARSDEN, P.D. et al. Studies on the domestic ecology of Triatoma infestans by means of house demolition. Rev. Inst. Med. trop. S. Paulo, 21:13-25, 1979.

28. MINTER, D.M. Feeding patterns of some triatominae vectors. In: International Symposium on New Approaches in American Trypanosomiasis Rescarch, Belo Horizonte, 1975. Proceedings. Washington, D.C., Pan American Health Organization, 1976. p. 33-47. (РAHO. Scient. publ., 318). 
FORATTINI, O.P. et al. Hábitos alimentares, infecção natural e distribuição de triatomíneos domiciliados na região central do Brasil. Rev. Saúde públ., S. Paulo, 16:171-204, 1982.

29. MOREIRA, A.A.N. \& CAMELIER, C. Relevo. In: Fundação IBGE. Geografi do Brasil: região sudeste. Rio de Janeiro. 1977 , ․ 3, p. 1-50.

30. NIMER, E. Climatologia do Brasil. Rio de Janeiro, SUPREN, 1979.

31. NIMER, E. Um modelo metodológico de classificação de climas. Rev. bras. Geogr., Rio de Janeiro. 41:59-89, 1979.

32. ROCHA e SILVA, E.O. da et al. Preferência alimentar (entre sangue humano e ave) dos Triatoma sordida encontrados em casas habitadas da região norte do Estado de São Paulo, Brasil. Rev. Saúde públ., S. Paulo, 11:258-69, 1977.

33. SANTOS, L.B. dos Aspecto geral da vegetação do Brasil. Bol. geogr., 1:68-73, 1943.
34. SANTOS. L.D. dos et al. Vegetação. In: Fundaçẫo IBGE. Geografia do Brasil: região centro-oeste. Rio de Janeiro, 1977. v. 4. p. 59-84.

35. SCHOFIELD, C.J. The behaviour of Triatominae (Hemiptera: Reduvidae): a review. Bull. ent. Res., 69:363-79, 1979.

36. SCHOFIELD, C.J. Nitritional status of domestic populations of Triatoma infestans. Trans. roy. Soc. trop. Med. Hyg., it: $770-8,1980$.

37. WEIBEL, L. A vegetação e o uso da terra no planalto central. Rev. bras. Geogr., $10: 335-71.1948$.

Recebido para publicação em 28/04/1982

Aprovado para publicação em 28/06/1982 
FORATTINI, O.P. et al. Hábitos alimentares, infeç̧ão natural e distribuição de triatomineos domiciliados na região central do Brasil. kev. Saúde pübl., S. Paulo, 16:171-204, 1982.

\section{ANEXOS}

Relação dos municípios de procedência do material examinado, distribuídos por Estados, por feições paisagísticas, e com a distribuição das espécies de triatomíneos encontradas.

$\mathrm{O}$ número de localidades pesquisadas figura entre parênteses.

ESTADO DE GOIÁS

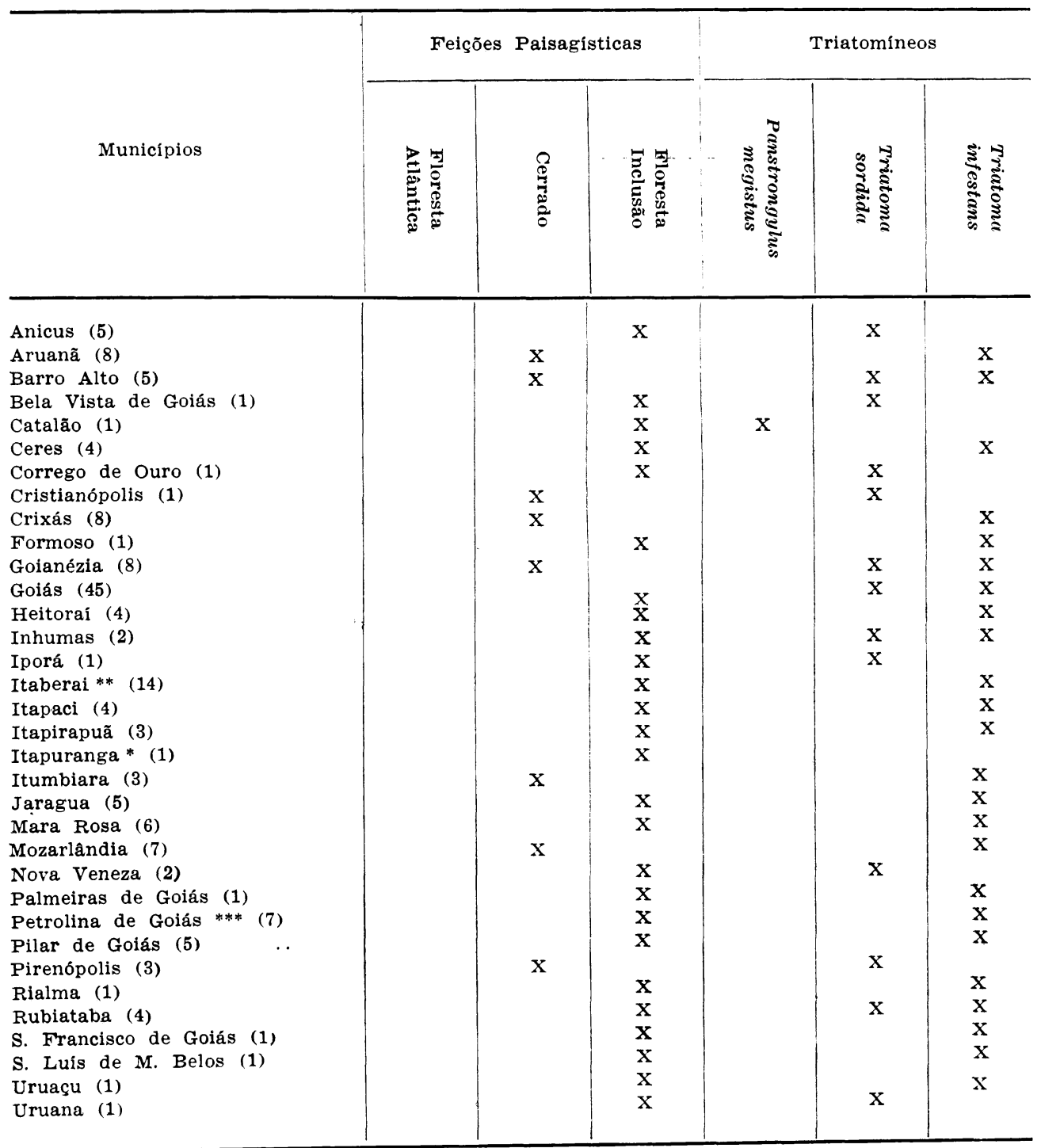

* Inclui-se 1 (um) exemplar de $R$. neglectus.

** Inclui-se 4 (quatro) exemplares de T. pseudomaculata e 1 (um) exemplar de $R$. neglectus.

*** Inclui-se 1 (um) exemplar de $R$. nasutus e 1 (um) de $R$. neglectus (Vide texto). 
FORATTINI, O.P. et al. Hábitos alimentares, infeç̧ăo natural e distribuição de triatomíneos domiciliados na região central do Brasil. Rev. Saúde públ., S. Paulo, 16:171-204, 1982.

\section{ESTADO DO MARANHAOO}

\begin{tabular}{|c|c|c|c|c|c|c|c|c|}
\hline \multirow[b]{2}{*}{ Municipios } & $\begin{array}{l}\text { Feicōes } \\
\text { paisa- } \\
\text { gisticas }\end{array}$ & \multicolumn{7}{|c|}{ Triatomíneos } \\
\hline & 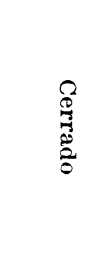 & 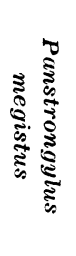 & 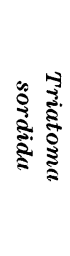 & 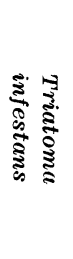 & 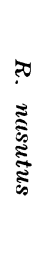 & 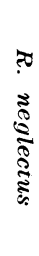 & 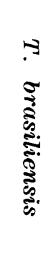 & 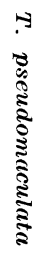 \\
\hline $\begin{array}{l}\text { Barão de } \\
\text { Grajau (1) }\end{array}$ & $\mathrm{x}$ & & & & & & $\mathrm{x}$ & \\
\hline Loreto (5) & $\mathrm{x}$ & $\mathrm{x}$ & & & & & $\mathrm{x}$ & \\
\hline $\begin{array}{l}\text { S. Felix de } \\
\text { Balsas (6) }\end{array}$ & $\mathrm{x}$ & & & & & & & $\mathrm{x}$ \\
\hline $\begin{array}{l}\text { S. João dos } \\
\text { Patos (4) }\end{array}$ & $\mathrm{x}$ & & & & & & & $\mathrm{x}$ \\
\hline
\end{tabular}

\section{ESTADO DE MINAS GERAIS}

\begin{tabular}{|c|c|c|c|c|c|c|}
\hline \multirow[b]{2}{*}{ Municípios } & \multicolumn{3}{|c|}{ Feições Paisagísticas } & \multicolumn{3}{|c|}{ Triatomíneos } \\
\hline & 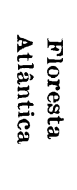 & 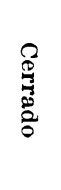 & 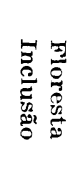 & 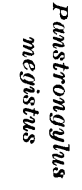 & 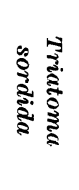 & 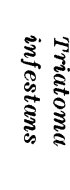 \\
\hline $\begin{array}{l}\text { Abadia dos Dourados (1) } \\
\text { Abaeté (5) } \\
\text { Agua Comprida (6) } \\
\text { Alvorada de Minas (1) } \\
\text { Antonio Dias (3) } \\
\text { Araguari (2) } \\
\text { Arapua (4) } \\
\text { Araxá (5) } \\
\text { Arcos (5) } \\
\text { Augusto de Lima (25) }\end{array}$ & $\mathrm{x}$ & $\begin{array}{l}x \\
X \\
y\end{array}$ & $\begin{array}{l}x \\
x\end{array}$ & $\begin{array}{l}\mathrm{x} \\
\mathrm{x} \\
\mathrm{x} \\
\mathrm{x} \\
\mathrm{x} \\
\mathrm{x} \\
\mathrm{x} \\
\mathrm{x}\end{array}$ & $\begin{array}{l}x \\
x\end{array}$ & $\mathrm{x}$ \\
\hline
\end{tabular}


FORATTINI, O.P. et al. Hábitos alimentares, infeção natural e distribuição de triatomineos domiciliados na regiäo central do Brasil. Eev. Saúde públ., S. Paulo, 16:171-204, 1982.

ESTADO DE MINAS GERAIS (continuação)

\begin{tabular}{|c|c|c|c|c|c|c|}
\hline \multirow[b]{2}{*}{ Municípios } & \multicolumn{3}{|c|}{ Feições Paisagísticas } & \multicolumn{3}{|c|}{ Triatomineos } \\
\hline & 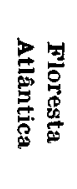 & $\begin{array}{l}\frac{8}{9} \\
\frac{9}{0} \\
\frac{8}{8}\end{array}$ & 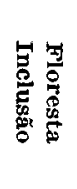 & 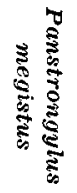 & 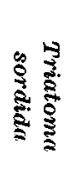 & 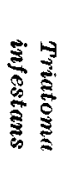 \\
\hline Baldim (1) & & $\mathrm{x}$ & & & $\mathrm{x}$ & \\
\hline Biquinhas (4) & & $\mathrm{x}$ & & $\mathrm{x}$ & $\alpha$ & \\
\hline Bocaiura (41) & & $\mathrm{x}$ & & $\mathrm{x}$ & $\mathrm{x}$ & $\mathrm{x}$ \\
\hline Bom Sucesso (1) & & $\mathrm{x}$ & & $\mathrm{x}$ & & \\
\hline Botumirim (15) & & $\mathrm{x}$ & & $\mathrm{x}$ & $\mathrm{x}$ & $\mathrm{x}$ \\
\hline Brasilia de Minas (53) & & $\mathrm{x}$ & & $\mathrm{x}$ & $\mathbf{x}$ & $\mathrm{x}$ \\
\hline Brumadinho (1) & $\mathrm{x}$ & & & $\mathrm{x}$ & & \\
\hline Brunópolis (30) & & $\mathrm{x}$ & & $\mathrm{x}$ & $\mathrm{x}$ & $\mathrm{x}$ \\
\hline Buritizeiro (9) & & $\mathrm{x}$ & & & $\mathrm{x}$ & $\mathrm{x}$ \\
\hline Campina Verde (15) & & $x$ & & & $\mathrm{x}$ & $\mathrm{x}$ \\
\hline Campo Florido (1) & & $\mathrm{x}$ & & & $\mathrm{x}$ & \\
\hline Capinópolis (1) & & $\mathrm{x}$ & & & $\mathrm{x}$ & \\
\hline Capitão Eneas (1) & & $\mathrm{x}$ & & & $\mathrm{x}$ & \\
\hline Capitólio (2) & & $\mathrm{x}$ & & $\mathrm{x}$ & & \\
\hline Carmo do Paranaiba (6) & & & $\mathrm{x}$ & $\mathrm{x}$ & & \\
\hline Carmópolis de Minas (3) & $\mathrm{x}$ & & & $\mathrm{x}$ & & \\
\hline Cascalho Rico (1) & & & $\mathrm{x}$ & $\mathrm{x}$ & & \\
\hline Centralina (3) & & $\mathrm{x}$ & & & $\mathrm{x}$ & $\mathrm{x}$ \\
\hline Claudio (1) & $\mathrm{x}$ & & & $\mathrm{x}$ & & \\
\hline Claro dos Pos̃̃es (6) & & $\mathrm{x}$ & & $\mathrm{x}$ & $\mathrm{x}$ & \\
\hline Conceição de Alagoas (14) & & $\mathrm{x}$ & & & $\mathrm{x}$ & $\mathrm{x}$ \\
\hline Conceição de M. Dentro (13) & & $\mathrm{x}$ & & $\mathrm{x}$ & & \\
\hline Conceição do Pará (2) & & & $\mathrm{x}$ & $\mathbf{x}$ & & \\
\hline Coração de Jesus (16) & & $\mathrm{x}$ & & $\mathrm{x}$ & $\mathrm{x}$ & $\mathrm{x}$ \\
\hline Cordisburgo (11) & & $\mathrm{x}$ & & $\mathbf{x}$ & $\mathrm{x}$ & \\
\hline Corinto (37) & & $\mathrm{x}$ & & $\mathrm{x}$ & $\mathrm{x}$ & $\mathbf{x}$ \\
\hline Cristália (1) & & $\mathrm{x}$ & & & & $\mathrm{x}$ \\
\hline Cruzeiro da Fortaleza (1) & & & $\mathrm{x}$ & $\mathrm{x}$ & $\mathrm{x}$ & \\
\hline Curvelo (33) & & $\mathrm{x}$ & & $\mathrm{x}$ & $\mathrm{x}$ & $\mathrm{x}$ \\
\hline Delfinópolis (1) & & $\mathbf{x}$ & & $\mathrm{x}$ & & \\
\hline Dionisio (2) & $\mathrm{x}$ & & & $\mathrm{x}$ & & \\
\hline Divinópolis & & & $\mathrm{x}$ & $\mathbf{x}$ & & \\
\hline Dom Silvério (4) & $\mathrm{x}$ & & & $\mathrm{x}$ & & \\
\hline Dores do Indaia (1) & & $\mathbf{x}$ & & $\mathrm{x}$ & & \\
\hline Esmeraldas (12) & & & $\mathrm{x}$ & $\mathrm{x}$ & & \\
\hline Espinosa & & $\mathrm{x}$ & & $\mathrm{x}$ & $\mathrm{x}$ & $\mathbf{x}$ \\
\hline Estrela do Indaia (1) & & $\mathrm{x}$ & & $\mathrm{x}$ & & \\
\hline Felixlândia $(8)$ & & $\mathrm{x}$ & & & $\mathrm{x}$ & \\
\hline Ferros (3) & $\mathrm{x}$ & & & $\mathrm{x}$ & & \\
\hline Florestal (6) & & & $\mathbf{x}$ & $\mathrm{x}$ & & \\
\hline Formiga (6) & & & $\mathrm{x}$ & $\mathrm{x}$ & & \\
\hline Francisco Sá (32) & & $\mathrm{x}$ & & $\mathrm{x}$ & $\mathrm{x}$ & $\underset{r}{x}$ \\
\hline Fronteira (2) & & $\mathrm{x}$ & & & & $\mathrm{x}$ \\
\hline Frutal (8) & & $\mathrm{x}$ & & & $\mathrm{x}$ & $\mathrm{x}$ \\
\hline Funilândia (4) & & $\mathrm{x}$ & & $\mathrm{x}$ & $\mathrm{x}$ & \\
\hline Grão Mogol (19) & & $\mathrm{x}$ & & $\mathrm{x}$ & & $\mathrm{x}$ \\
\hline
\end{tabular}


FORATTINI, O.P. et al. Hábitos alimentares, infecção natural e distribuição de triatomineos domiciliados na regtão central do Brasil. Rev. Saúde pübl., S. Paulo, 16:171-204, 1982.

ESTADO DE MINAS GERAIS (continuação)

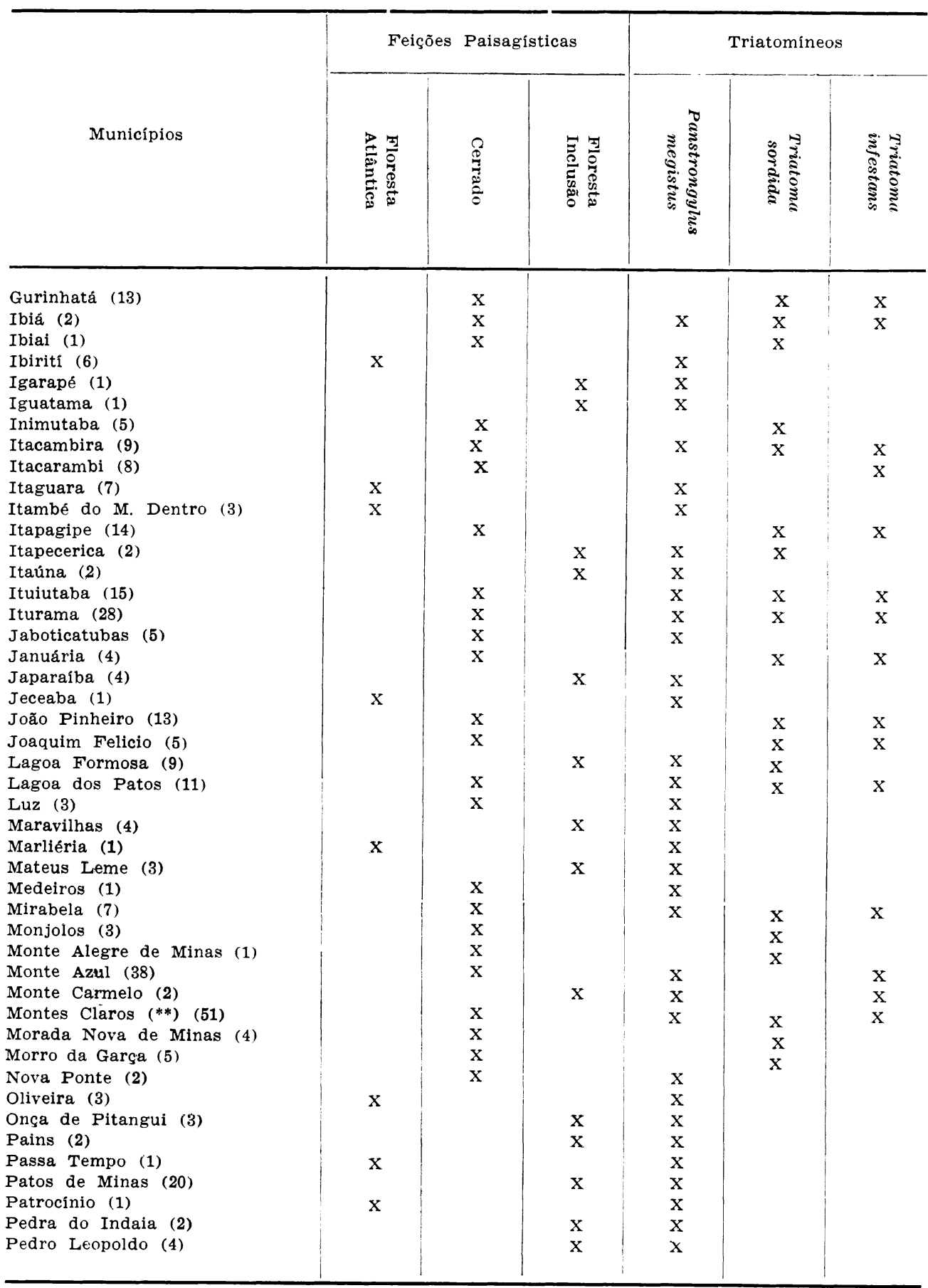


FORATTINI, O.P. et al. Hábitos alimentares, infeçãa natural e distribuição de triatomíneos domiciliados na região central do Brasil. Rev. Saúde públ., S. Paulo, 16:171-204, 1982.

\section{ESTADO DE MINAS GERAIS (continuação)}

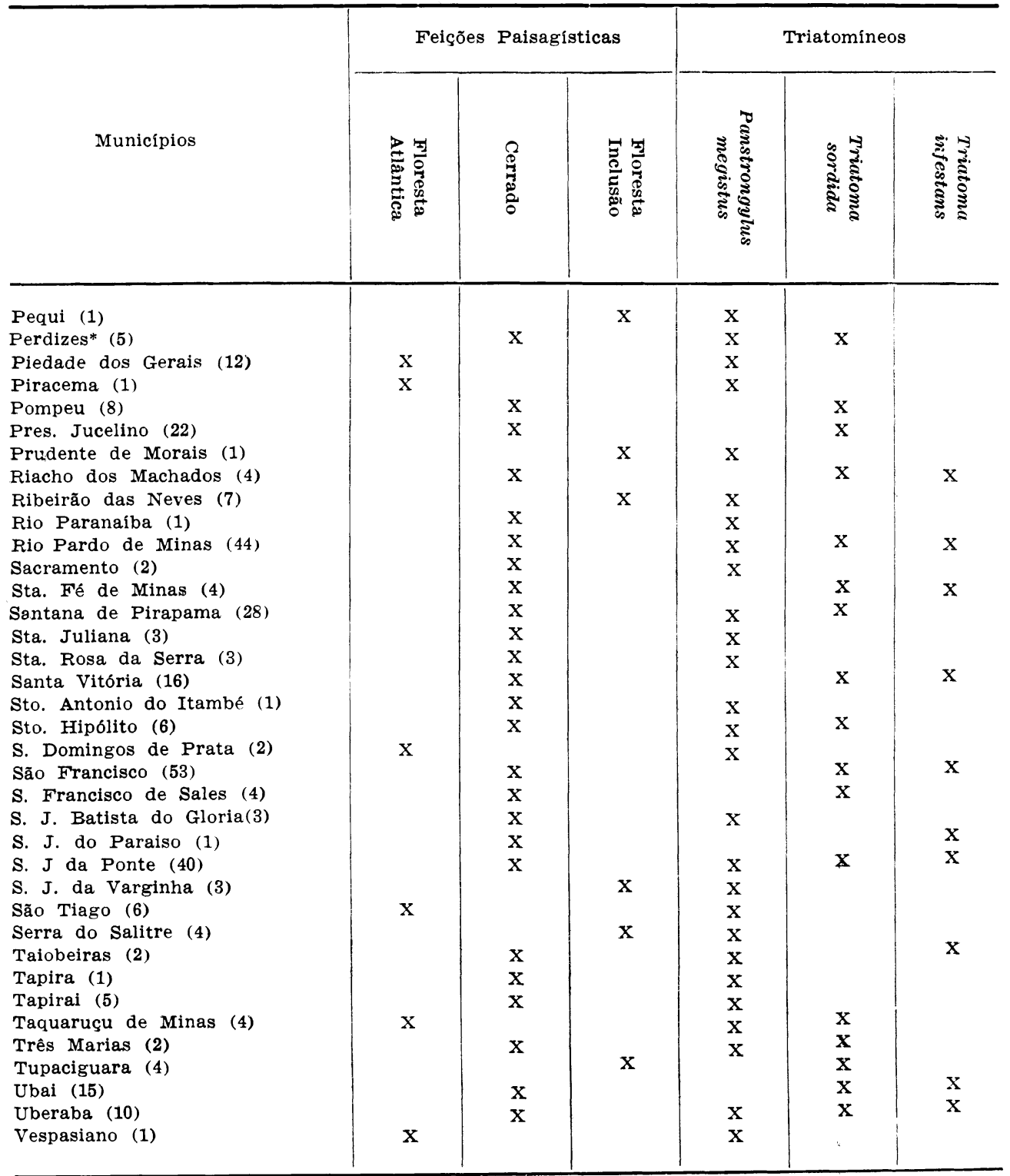

* Inclui-se 1 (um) exemplar de $R$. neglectus (Vide texto).

* Inclui-se 1 (um) exemplar de $R$. nasutus e 1 (um) de $R$. neglectus (Vide texto). 
FORATTINI, O.P. et al. Hábitos alimentares, infeç̧ão natural e distribuição de triatomíneos domiciliados na regiăo central do Brasil. Rev. Saúde públ., S. Paulo, 16:171-204, 1982.

\section{ESTADO DE MATO GROSSO DO SUL}

\begin{tabular}{|c|c|c|c|c|c|}
\hline \multirow[b]{2}{*}{ Municipios } & \multicolumn{2}{|c|}{ Feiçōes paisagísticas } & \multicolumn{3}{|c|}{ Triatomíneos } \\
\hline & 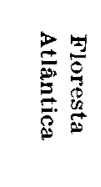 & 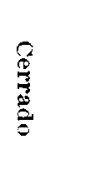 & 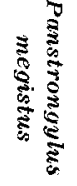 & 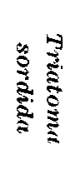 & 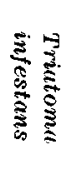 \\
\hline $\begin{array}{l}\text { Aparecida do Taboado (6) } \\
\text { Bandeirantes (2) } \\
\text { Brasilândia (4) } \\
\text { Caarapó (3) } \\
\text { Camapua (8) } \\
\text { Campo Grande (1) } \\
\text { Corumbá (2) } \\
\text { Coxim (2) } \\
\text { Dourados (20) } \\
\text { Fátima do Sul (18) } \\
\text { Glória de Dourados (9) } \\
\text { Itapora (1) } \\
\text { Jaraguari (2) } \\
\text { Jatei (2) (1) } \\
\text { Maracaju (1) } \\
\text { Paranaiba (4) } \\
\text { Pedro Gomes(1) } \\
\text { Rio Negro (1) } \\
\text { R. Verde de M. Grosso (5) } \\
\text { Très Lagoas (6) }\end{array}$ & $\begin{array}{l}x \\
x\end{array}$ & $\begin{array}{l}x \\
x \\
x \\
x \\
x \\
x \\
x \\
x \\
x\end{array}$ & & $\begin{array}{l}\mathrm{X} \\
\mathrm{X} \\
\mathrm{x} \\
\mathrm{x} \\
\mathrm{x} \\
\mathrm{x}\end{array}$ & $\begin{array}{l}\mathrm{x} \\
\mathrm{x} \\
\mathrm{x} \\
\mathrm{x} \\
\mathrm{x} \\
\mathrm{x} \\
\mathrm{x} \\
\mathrm{x} \\
\mathrm{x} \\
\mathrm{x} \\
\mathrm{x} \\
\mathrm{x} \\
\mathrm{x}\end{array}$ \\
\hline
\end{tabular}

